Pacific Northwest

National Laboratory

Operated by Battelle for the

U.S. Department of Energy

\title{
Optimal Elevation and Configuration of Hanford's Double-Shell Tank Waste Mixer Pumps
}

\author{
Y. Onishi \\ S.T. Yokuda \\ C.H. Majumder
}

May 2002

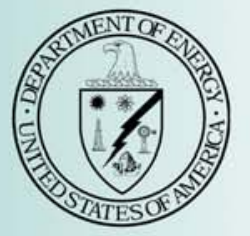




\section{DISCLAIMER}

This report was prepared as an account of work sponsored by an agency of the United States Government. Neither the United States Government nor any agency thereof, nor Battelle Memorial Institute nor any of their employees makes any warranty, express or implied, or assumes any legal liability or responsibility for the accuracy, completeness, or usefulness of any information, apparatus, product, or process disclosed or represents that its use would not infringe privately owned rights. Reference herein to any specific commercial product, process, or service by trade name, trademark, manufacturer, or otherwise does not necessarily constitute or imply its endorsement, recommendation, or favoring by the United States Government or any agency thereof, or Battelle Memorial Institute. The views and opinions of authors expressed herein do not necessarily state or reflect those of the United States Government or any agency thereof.

\section{PACIFIC NORTHWEST NATIONAL LABORATORY \\ operated by \\ BATTELLE \\ for the \\ UNITED STATES DEPARTMENT OF ENERGY \\ under Contract DE-AC06-76RL01830}

Printed in the United States of America

Available to DOE and DOE contractors from the

Office of Scientific and Technical Information,

P.O. Box 62, Oak Ridge, TN 37831-0062;

ph: (865) 576-8401

fax: (865) 576-5728

email: reports@adonis.osti.gov

Available to the public from the National Technical Information Service,

U.S. Department of Commerce, 5285 Port Royal Rd., Springfield, VA 22161

ph: (800) 553-6847

fax: (703) 605-6900

email: orders@ntis.fedworld.gov

online ordering: http://www.ntis.gov/ordering.htm 


\section{Optimal Elevation and Configuration of Hanford's Double-Shell Tank Waste Mixer Pumps}

Y. Onishi

S. T. Yokuda

C.H. Majumder ${ }^{(a)}$

May 2002

Prepared for the U.S. Department of Energy under Contract DE-AC06-76RLO 1830

Pacific Northwest National Laboratory

Richland, WA 99352

(a) University of Minnesota 


\section{Summary}

A horizontal jet injected from near the tank bottom may potentially erode more sludge and saltcake than a jet placed away from the bottom. Placing the intake at the top of a centrifugal pump also potentially makes it easier to start up mixer pumps. However, a higher inlet can limit the operable range of the waste thickness and may reduce solid erosion by drawing lighter fluids into the pump, which would make the mixer pump jet more buoyant. A baseline mixer pump of Hanford double-shell tank has an intake at the bottom and injection nozzles at the top. A Lawrence pump installed in Tank 241-AZ-101 represents the baseline pump.

The objectives of the study were to 1) compare the mixing performance of the baseline pump (represented by the Lawrence pump installed in Tank 241-AZ-101) with an alternative pump that has the inlet at the top and injection nozzles at the bottom, and 2) determine the optimal elevation of the alternative pump if its performance in eroding the waste is better than that of the baseline pump.

We evaluated a total of 16 cases of baseline and alternative pump conditions with pumps situated at levels ranging from the tank bottom to 32.7 inches $(0.83 \mathrm{~m})$ above the tank bottom, and sludge thicknesses of 22 inches $(0.56 \mathrm{~m})$ and 125 inches $(3.17 \mathrm{~m})$. We assigned waste properties that are the same as those of Tank 241-AZ-102 sludge because it is more difficult to mobilize sludge than saltcake, and thus the results would be more indicative of the pump's erosion ability. This study used a two-step evaluation approach: Step 1 evaluated all 16 cases with the non-rotating mixer pump model and Step 2 further evaluated four of those 16 cases with the more realistic rotating mixer pump model. We applied the TEMPEST code to these models.

According to the non-rotating mixer pump model simulation results, the elevation of the pump intake by itself does not affect the pumps' erosion capability when the injection nozzles of both baseline and alternative pumps were placed at the baseline nozzle's injection level $(0.43 \mathrm{~m})$. Model results from 14 alternative pump cases indicate that the closer the pump's injection elevation is to the tank bottom, the greater the sludge erosion. When the injection nozzles of the alternative pump are placed on the tank bottom or 1.5 inches $(0.038 \mathrm{~m})$ above the bottom, the pump mobilizes $200 \sim 900 \%$ and $140 \sim 450 \%$, respectively, more sludge than the baseline pump. Thus the alternative pump can be more effective than the baseline pump because its injection nozzles can be placed lower than those of the baseline pump. There may, however, be some engineering difficulties with placing 300-hp mixer pumps closer than about 6 inches $(0.15 \mathrm{~m})$ to the tank bottom. Thus, pump elevations between 3 and 6 inches $(0.074$ and $0.15 \mathrm{~m})$ were further evaluated under Step 2.

Similar to the non-rotating mixer pump model results, the more realistic simulation results with the rotating mixer pump model indicated that the alternative pump installed 2.9 inches $(0.074 \mathrm{~m}), 4.6$ inches $(0.116 \mathrm{~m})$, and 6.2 inches $(0.159 \mathrm{~m})$ above the tank bottom mobilized almost the same amount of solids; they eroded approximately $10 \sim 12$ vol\% more of the total tank solids than a reference case [an alternative pump installed at 16.9 inches $(0.43 \mathrm{~m})]$. Relatively speaking, these three lower-elevation cases would erode $25 \sim 33 \%$ more solids than 
the reference case. These results provide a mixing performance technical basis for the $\mathrm{W}-211$ Project, "Initial Tank Retrieval Systems," to determine which pump configuration should be used for their double-shell tank waste retrieval activity. 


\section{Contents}

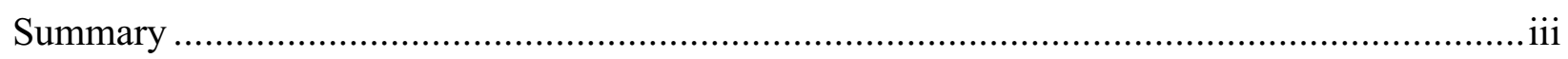

1.0 Introduction

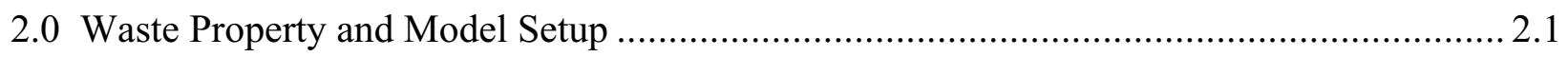



2.2 Pump Elevation Positions and Waste Thickness …….................................................... 2.3

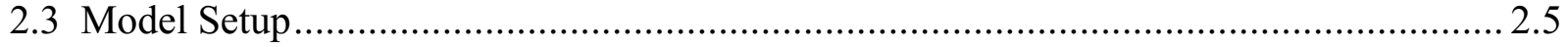



3.1 Mixing Performance Comparison of Pumps with Bottom or Top Intake ......................... 3.2

3.2 Optimal Elevation of Alternative Pump Placement ........................................................... 3.9

4.0 Rotating Mixer Pump Model Results............................................................................ 4.1



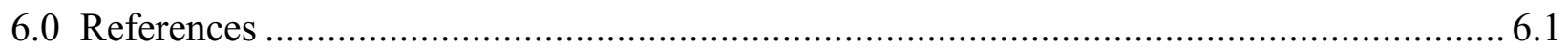




\section{Figures}

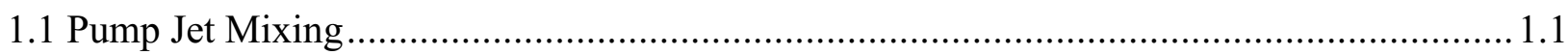

2.1 AZ-102 Tank Waste Volume-Based Particle Size Distribution......................................2.2.2

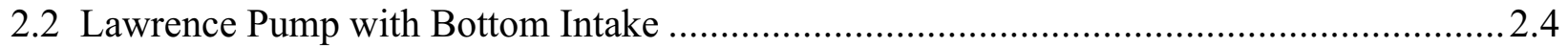

2.3 Example (a Sulzer pump) Alternative Pump with Top Intake ..................................... 2.4

2.4 Double-Shell Tank with Two Rotating Mixer Pumps ................................................... 2.6

3.1 Case 1: Initial Horizontal and Vertical Distributions of Velocity and Tank Waste .............3.3

3.2 Case 1: Predicted Horizontal and Vertical Distributions of Velocity and Solid



3.3 Case 2: Predicted Horizontal and Vertical Distributions of Velocity and Solid Volume Fraction at 20 Simulation Minutes ....................................................... 3.6

3.4 Case 3: Predicted Horizontal and Vertical Distributions of Velocity and Solid Volume Fraction at 20 Simulation Minutes........................................................................ 3.7

3.5 Case 4: Predicted Horizontal Alternative Pump with 3.17-m Sludge Distributions of Velocity and Solid Volume Fraction at 20 Simulation Minutes ................................ 3.8

3.6 Case 5: Predicted Horizontal and Vertical Distributions of Velocity and Solid Volume Fraction at 20 Simulation Minutes

3.7 Case 6: Predicted Horizontal and Vertical Distributions of Velocity and Solid Volume Fraction at 20 Simulation Minutes

3.8 Case 7: Predicted Horizontal and Vertical Distributions of Velocity and Solid Volume Fraction at 20 Simulation Minutes

3.9 Case 8: Predicted Horizontal and Vertical Distributions of Velocity and Solid Volume Fraction at 20 Simulation Minutes

3.10 Case 9: Predicted Horizontal and Vertical Distributions of Velocity and Solid Volume Fraction at 20 Simulation Minutes

3.11 Case 10: Predicted Horizontal and Vertical Distributions of Velocity and Solid Volume Fraction at 20 Simulation Minutes

3.12 Case 11: Predicted Horizontal and Vertical Distributions of Velocity and Solid Volume Fraction at 20 Simulation Minutes

3.13 Case 12: Predicted Horizontal and Vertical Distributions of Velocity and Solid Volume Fraction at 20 Simulation Minutes

3.14 Case 13: Predicted Horizontal and Vertical Distributions of Velocity and Solid Volume Fraction at 20 Simulation Minutes

3.15 Case 14: Predicted Horizontal and Vertical Distributions of Velocity and Solid Volume Fraction at 20 Simulation Minutes

3.16 Case 15: Predicted Horizontal and Vertical Distributions of Velocity and Solid Volume Fraction at 20 Simulation Minutes

3.17 Case 16: Predicted Horizontal and Vertical Distributions of Velocity and Solid Volume Fraction at 20 Simulation Minutes 
3.18 Predicted Mobilized Sludge Volume Percent Compared with Initial Total Sludge Volume for Sludge Thickness of 125 inches

3.19 Predicted Vol\% of Eroded Sludge Normalized by Case 3:

Sludge Thickness 125 inches

3.20 Predicted Mobilized Sludge Volume Percent Compared with Initial

Total Sludge Volume for Sludge Thickness of 23 inches

3.21 Vol\% of Eroded Sludge Normalized by Case 4: Sludge Thickness 23 inches.............. 3.26

4.1 Case 3: Initial Vertical Distributions of Velocity and Tank Waste

4.2 Case 3: Predicted Vertical Distributions of Velocity and Solid Volume Fraction at 70 Simulation Minutes

4.3 Case 7: Predicted Vertical Distributions of Velocity and Solid Volume Fraction at 70 Simulation Minutes

4.4 Case 8: Predicted Vertical Distributions of Velocity and Solid Volume Fraction at 70 Simulation Minutes

4.5 Case 9: Predicted Vertical Distributions of Velocity and Solid Volume Fraction at 70 Simulation Minutes

4.6 Predicted Mobilized Sludge Volume Percent Compared with Initial Total Sludge Volume for Sludge Thickness of 125 inches

4.7 Predicted Vol\% of Eroded Sludge Normalized by Case 3 for Sludge Thickness of 125 inches

\section{Tables}

2.1 Pump Injection Nozzle and Withdrawal Inlet Elevation Levels.................................2.5



3.2 Summary of Baseline Lawrence and Corresponding Alternative Pump Cases.................3.9

3.3 Summary of Sludge Erosion Based on Non-Rotating Pump Model Results .................3.23

4.1 Summary of Alternative Pump Reference Case (Case 3) and Cases 7 through 9 ............ 4.3

5.1 Summary of Alternative Pump Cases ........................................................................ 5.2 


\subsection{Introduction}

Many radioactive wastes are stored in double-shell tanks (DSTs) at the U.S. Department of Energy's Hanford Site in southeastern Washington. These wastes are multicomponent and multiphase, consisting of saltcake, sludge, liquid, and possibly gases (Gephart and Lundgren 1997). One or two mixer pumps would be installed in each DST to mix these wastes to retrieve them from the tanks (see Figure 1.1 showing single mixer pump installed in a tank). The mixer pump withdraws the waste from the tank and injects it back into the tank through two opposing, rotating, injection nozzles to mix the solids and liquids. A 300-hp Lawrence pump has been considered as the baseline pump. It is a centrifugal pump with a 17-inch- $(0.43-\mathrm{m}-)$ diameter intake at the bottom and two 6-inch- (0.15-m-) diameter nozzles injecting 60-f/sec $(18.3-\mathrm{m} / \mathrm{s})$ jets 11 inches $(0.28 \mathrm{~m})$ above the pump intake. The baseline (Lawrence) pump was installed in Hanford DST 241-AZ-101 with pump intake and injection nozzles 7 inches $(0.18 \mathrm{~m})$ and 18 inches $(0.46 \mathrm{~m})$, respectively, above the tank bottom (Carlson et al. 2001).

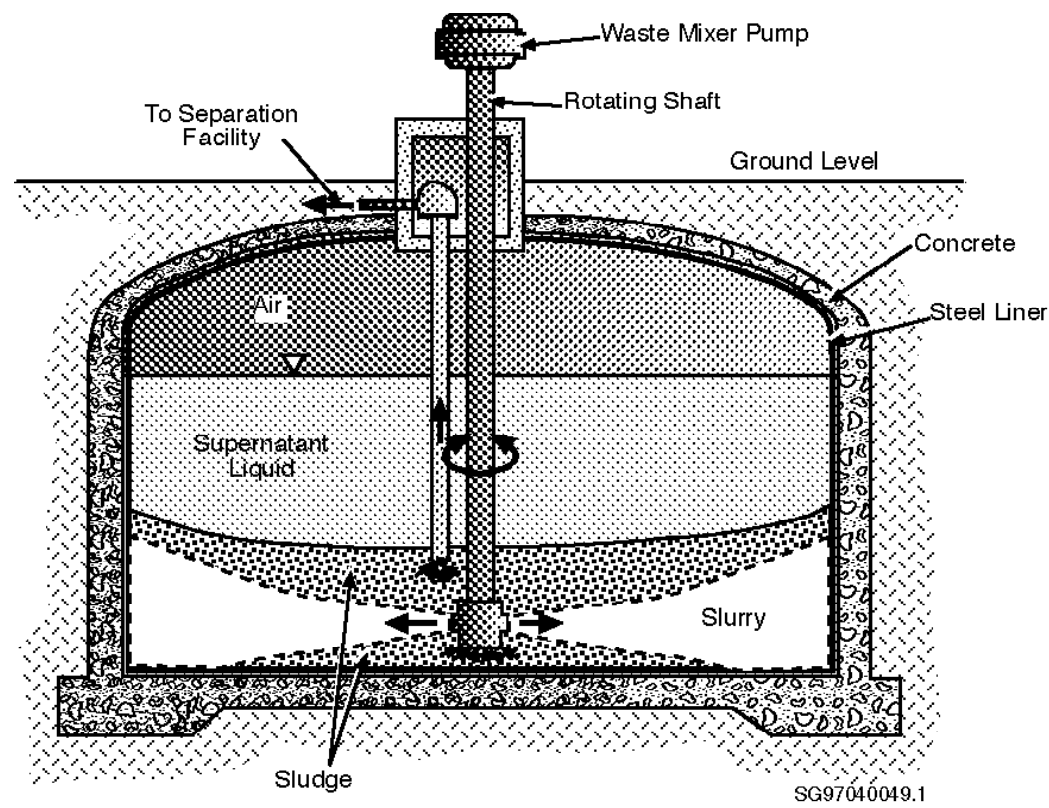

Figure 1.1. Pump Jet Mixing

Many saltcake and sludge DST wastes have yield strength and high viscosity ${ }^{(a)}$ (Onishi et al. 2000; Jewett et al. 2002). For example, saltcakes in Tanks AN-104 and AN-105 have a yield strength of approximately 50 to $200 \mathrm{~Pa}$ and viscosity that can exceed several million centipoise (Stewart et al. 1996). Some sludge has much greater yield strength, such as Tank AZ-102's sludge with yield strength of 1,560 $\mathrm{Pa} .{ }^{\text {(a) }}$ Most of the DST saltcake and sludge wastes exhibit

(a) Gray WJ, ME Peterson, RD Scheele, and JM Tingey. 1993. Characterization of the First Core Sample of Neutralized Current Acid Waste from Double-Shell Tank AZ-102. Pacific Northwest National Laboratory, Richland, WA (unpublished report). 
non-Newtonian, shear-thinning behavior (i.e., slurry viscosity decreases with strain rate) (Onishi et al. 1996). For a given saltcake and sludge, the higher the solids concentration, the greater the viscosity (Onishi et al. 1996; Jewett et al. 2002). Water is expected to be added as a diluent (solvent) to DSTs containing saltcake to dissolve much of the soluble solids [e.g., $\mathrm{NaNO}_{3}(\mathrm{~s})$, $\left.\mathrm{Na}_{2} \mathrm{CO}_{3} \bullet \mathrm{H}_{2} \mathrm{O}(\mathrm{s}), \mathrm{Na}_{2} \mathrm{SO}_{4}(\mathrm{~s})\right]$, thus making it easier for the mixer pumps to mix the wastes.

To mobilize these sludges and saltcakes, mixer pumps must overcome their yield strength and high viscosity and mix the sludge and saltcake with the overlying liquid waste. Moreover, centrifugal pumps, including the Lawrence pump, are generally not designed to handle slurry with viscosity higher than $1,000 \mathrm{cP}$. Thus, the mixer pumps may face the additional difficulty of starting up when the pump withdraws the high-viscosity waste in the immediate vicinity of the pump. Injecting water and producing a water pool around the mixer pumps prior to pump operation would reduce waste viscosity and maybe even eliminate the yield strength of the sludge and saltcake near the mixer pumps (Onishi et al. 1996, 2000). That would make it easier to start up the pumps, but the original sludge and saltcake may crumble, depending on its yield strength, so it may not be possible to keep water around the pumps. Thus, during and after water lancing but prior to mixer pump operation, the waste viscosity increases near the tank bottom as solids (those remaining after soluble solids are dissolved) settle toward the tank bottom. The longer the time after water lancing and the closer to tank bottom, the greater the waste viscosity. Thus, placing the pump inlet higher in the tank can make the pump startup easier.

Experimental studies of homogeneous jets (an air jet injected into air and a water jet injected into water) indicate that the horizontal jets injected near the solid bottom have faster centerline velocities at a given downstream distance (Rajaratnam and Subramanya 1968; Pani and Dash 1983). Thus a horizontal waste jet placed near the tank bottom may exert more force to overcome the yield strength, eroding more sludge and saltcake than the jet placed away from the bottom. Placing the waste intake at the top of the pump enables the injection nozzles to be placed at the bottom, closer to the tank bottom than the baseline pump with the injection nozzle at the top. Placing the inlet at the top of the centrifugal pump also potentially makes it easier to start up the mixer pumps when the vertical distribution of the solid concentrations is nonuniform, as stated above. However, a higher pump inlet can limit the operable range of the waste thickness and could reduce solid erosion by withdrawing lighter fluids (a liquid waste or a slurry with less solid concentration) and making the mixer pump jet more buoyant.

The objective of the study was to evaluate the performance of mixer pumps so that the W-211 Project, "Initial Tank Retrieval Systems," can determine whether its DST waste retrieval operation should use the baseline pumps, with injection nozzles at the top and inlet at the bottom, or alternative pumps, with injection nozzles at the bottom and the inlet at the top. To achieve this objective, we conducted three-dimensional TEMPEST computer simulations to answer the following questions:

- How much more solids, if any, can be mobilized by the alternative pump with injection nozzles at the pump bottom than with the baseline pump?

- If the alternative pump is more effective at mobilizing the solids than the baseline pump, what is the optimal elevation for its installation in a DST? 
Because three-dimensional simulations require a significant computation time (up to a few months of CPU time for each simulation with rotating mixer pumps), we adapted the following two-step approach to obtain a mixing performance evaluation in a timely manner:

Step 1: evaluate all 16 baseline and alternative pump cases with non-rotating mixer pump models and select four cases for further detailed evaluation

Step 2: evaluate the four selected cases with rotating mixer pump models to determine realistic mixing performance evaluation.

Section 2 presents the waste property and model setup used for this study. Section 3 describes the scoping evaluation with the non-rotating mixer pump models. The rotating mixer pump model results are discussed in Section 4. Summary and conclusions are presented in Section 5, while cited references are listed in Section 6. 


\subsection{Waste Property and Model Setup}

\subsection{Waste Properties}

The solid layers of DST wastes consist of saltcake and sludge, in addition to an interstitial liquid waste and possibly gases (Gephart and Lundgren 1997). Saltcakes consist of mostly soluble solids, and sludge contains more insoluble solids. In general, the solid layers with sludge have much greater yield strength than those with saltcake. For example, AZ-102 wastes are sludge with a yield strength of 1,560 Pa in most of the solid layers, ${ }^{(a)}$ while Tanks AN-104 and AN-105 wastes are saltcake wastes with yield strengths of $100 \sim 200 \mathrm{~Pa}$ and $50 \sim 150 \mathrm{~Pa}$, respectively (Stewart et al. 1996). Because the saltcakes contain many soluble solids, a current DST waste retrieval plan is to add water to a tank to dissolve much of the saltcake waste, while mixing the water with the saltcake with mixer pumps. As indicated in Section 1, the yield strength and viscosity of the diluted saltcakes are significantly less than those of undiluted saltcakes $^{\text {(a) }}$ (Herting 1997; Onishi et al. 1996) because solid concentrations in diluted saltcakes are less than in undiluted saltcakes. On the other hand, the sludge will not be diluted with water during retrieval operations, so it tends to be more difficult for mixer pumps to mobilize sludge waste than saltcake. Thus, for this mixer pump evaluation, we selected the properties of sludge for tank waste. The properties of Tank AZ-102 waste were used because it is representative of DST sludge, and detailed waste rheology measurements were available. ${ }^{(a)}$

Tank AZ-102 has a diameter and operating depth of $75 \mathrm{ft}(23 \mathrm{~m})$ and $35 \mathrm{ft}(10.7 \mathrm{~m})$, respectively. Its operational storage capacity is $1,160,000 \mathrm{gal}\left(4,390 \mathrm{~m}^{3}\right)$. The tank contains twenty 30-inch- (76-cm-) diameter airlift circulators and a 33-inch- (84-cm-) diameter steamheating coil that are no longer used. AZ-102 began receiving high-level aging waste from the PUREX Plant, high strontium waste from B Plant, and complex concentrated waste from the 242-A evaporator in 1976. In 1986, most of this waste was removed. After 1986, the tank received aging waste (neutralized current acid waste) from the PUREX Plant and wastewater. Although it still remains in active service, the tank last received an aging waste in 1990 (Ryan 1995). It contains 854,000 gal $\left(3,230 \mathrm{~m}^{3}\right)$ of supernatant liquid and $95,000 \mathrm{gal}\left(360 \mathrm{~m}^{3}\right)$ of sludge (Ryan 1995). The supernatant liquid and sludge occupy 310 inches $(7.87 \mathrm{~m})$ and 35 inches $(0.89 \mathrm{~m})$, respectively, of the total tank waste level of 345 inches $(8.76 \mathrm{~m})$. These volumes correspond to $90 \mathrm{vol} \%$ supernatant liquid and $10 \mathrm{vol} \%$ sludge. The average temperature of the supernatant liquid is $55^{\circ} \mathrm{C}$; the maximum sludge temperature is $83^{\circ} \mathrm{C}$.

The supernatant liquid density of the AZ-102 waste is $1,100 \mathrm{~kg} / \mathrm{m}^{3}$, and the bulk sludge density is $1,490 \mathrm{~kg} / \mathrm{m}^{3}$ (Ryan 1995). With the assigned solid volume concentration of $31 \%$ in the sludge layer and the bulk sludge density, the solid density was designated as $2,360 \mathrm{~kg} / \mathrm{m}^{3}$. This solid density was in line with the sludge expected to have $\mathrm{Al}(\mathrm{OH})_{3}(\mathrm{~s}), \mathrm{Na}_{2} \mathrm{SO}_{4}(\mathrm{~s}), \mathrm{NaF}(\mathrm{s})$, $\mathrm{Cr}(\mathrm{OH})_{3}(\mathrm{am}), \mathrm{SiO}_{2}(\mathrm{~s})$ among others (Onishi et al. 2000). Solid particle size varies from 0.5 to 13 $\mathrm{mm}$, with a medium size of $3.4 \mathrm{~mm}$ based on volume, as shown in Figure 2.1 (Ryan 1995).

(a) Gray WJ, ME Peterson, RD Scheele, and JM Tingey. 1993. Characterization of the First Core Sample of Neutralized Current Acid Waste from Double-Shell Tank AZ-102. Pacific Northwest National Laboratory, Richland, WA (unpublished report). 




Figure 2.1. AZ-102 Tank Waste Volume-Based Particle Size Distribution

The sludge has a yield strength of approximately 1,540Pa, except within a few centimeters of the tank bottom. ${ }^{(a)}$ Once the sludge is disturbed, the yield strength may be reduced to about $60 \mathrm{~Pa}$, roughly a 25 -fold reduction. When the sludge was mixed with 1.5 times the volume of the supernatant liquid, the yield strength of the mixture was reduced to $2 \mathrm{~Pa}$, a 770-fold reduction in yield from the undiluted sludge. When the supernatant liquid diluted the sludge by 10 times, the mixed slurry totally lost its yield strength. Thus the dilution of the sludge by the liquid significantly reduced the strength of the sludge to resist mobilization. In the current model, the yield strength of the sludge was designated as $1,560 \mathrm{~Pa}$, and the sludge was eroded when the normal and shear stresses generated by the pump jet (or jet-induced flow) exceeded the yield strength of the sludge.

The AZ-102 supernatant liquid viscosity is $1 \mathrm{cP}$ (Ryan 1995). The viscosity of the slurry changes spatially and temporally during the pump jet mixing operation, as supernatant liquid and solids mix with each other. Based on viscosity measurements reported by Gray et al. ${ }^{(a)}$ we assigned the slurry viscosity to vary with the solid volume concentration:

$$
\mu=\mu_{L}\left\{\frac{\mu_{s}}{\mu_{L}}\right\}^{\frac{C_{V}}{C_{V \max }}}
$$

where

$$
\mathrm{C}_{\mathrm{V}} \quad=\text { solid volume fraction of the slurry }
$$

(a) Gray WJ, ME Peterson, RD Scheele, and JM Tingey. 1993. Characterization of the First Core Sample of Neutralized Current Acid Waste from Double-Shell Tank AZ-102. Pacific Northwest National Laboratory, Richland, WA (unpublished report). 
$\mathrm{C}_{\mathrm{V} \max }=$ maximum solid volume fraction (=0.33 in this study)

$\mu \quad=$ viscosity of the slurry at solid concentration of $\mathrm{C}_{\mathrm{V}}$

$\mu_{\mathrm{L}} \quad=$ viscosity of the supernatant liquid ( $=1.0 \mathrm{cP}$ in this study)

$\mu_{\mathrm{S}} \quad=$ viscosity of the sludge layer $\left(426 \mathrm{cP}\right.$ when sludge moves at a strain rate of $\left.5 \mathrm{~s}^{-1}\right)$.

As shown in Figure 2.1, the AZ-102 solid size distribution varied from 1 to $11 \mu \mathrm{m}$, averaging $3.4 \mu \mathrm{m}$. Corresponding settling velocities are very small, $7.4 \times 10^{-7}, 9 \times 10^{-5}$, and $8.6 \times 10^{-6} \mathrm{~m} / \mathrm{s}$, respectively. As previous pump jet mixing studies indicate (Onishi et. al. 1996b; Onishi and Recknagle 1997, 1998; Whyatt et al. 1996), these settling velocities are much smaller than the expected slurry velocity induced by the pump jets in the tank. The resulting distributions of 1 to $11 \mathrm{~mm}$ solid particles are expected to be very similar to each other (Onishi et al. 2000). Thus we assigned a diameter of $3.4 \mu \mathrm{m}$ to all the solids for the current pump jet mixing modeling. Because the actual solid settling velocities will decrease with solids concentration, we designated the following hindering settling velocity as changing with the solid concentration during the simulation:

$$
V_{s}=V_{s o}\left(1-\frac{C_{V}}{C_{V \max }}\right)^{a}
$$

where

a $\quad=$ constant $(=4.7$ in this study based on the Stokes Law)

$\mathrm{V}_{\mathrm{s}} \quad=$ hindered setting velocity at solid volume fraction of $\mathrm{C}_{\mathrm{V}}$

$\mathrm{V}_{\mathrm{so}} \quad=$ unhindered setting velocity (settling velocity in clear liquid with no solids).

\subsection{Pump Elevation Positions and Waste Thickness}

Figure 2.2 shows an example of the baseline pump. It is a Lawrence pump with a 17 -inch(0.43-m-) diameter waste intake at the pump bottom and two 6-inch- $(0.15-\mathrm{m}-)$ diameter nozzles injecting $60-\mathrm{ft} / \mathrm{sec}(18.3 \mathrm{~m} / \mathrm{s})$ jets whose centerline is 11 inches $(0.28 \mathrm{~m})$ above the pump intake. The baseline pumps are to be placed in DSTs such that the intake and the centerline of the injection nozzle would be approximately 7 inches $(0.18 \mathrm{~m})$ and 18 inches $(0.46 \mathrm{~m})$, respectively, above the tank bottom.

An example (a Sulzer pump) of the alternative pump with the top intake is shown in Figure 2.3. This pump has two six-inch $(0.15-\mathrm{m})$ injection nozzles at the pump bottom and a 27 inch- $(0.67-\mathrm{m}-)$ diameter waste intake 21.5 inches $(0.55 \mathrm{~m})$ above the injection nozzle centerlines. We used this Sulzer pump as an alternative pump in this study.

The DST retrieval plan calls for two 300-hp mixer pumps to be installed in some DSTs at an equal distance of either $20 \mathrm{ft}(6.1 \mathrm{~m})$ (e.g., AN-104 and AN-105) or $22 \mathrm{ft}(6.7 \mathrm{~m})$ (e.g., AZ-101 and AZ-102) from the tank center on opposite sides of the tank. In other cases, only a single mixer pump would be installed at the tank center (e.g., for AP-102 and AP-104), or possibly offcenter. Many of these pumps would rotate at $0.2 \mathrm{rpm}$ and have two 6-inch $(15-\mathrm{cm})$ nozzles injecting $60-\mathrm{ft} / \mathrm{sec}(18.3 \mathrm{~m} / \mathrm{s})$ rotating jets to mix stored wastes. 


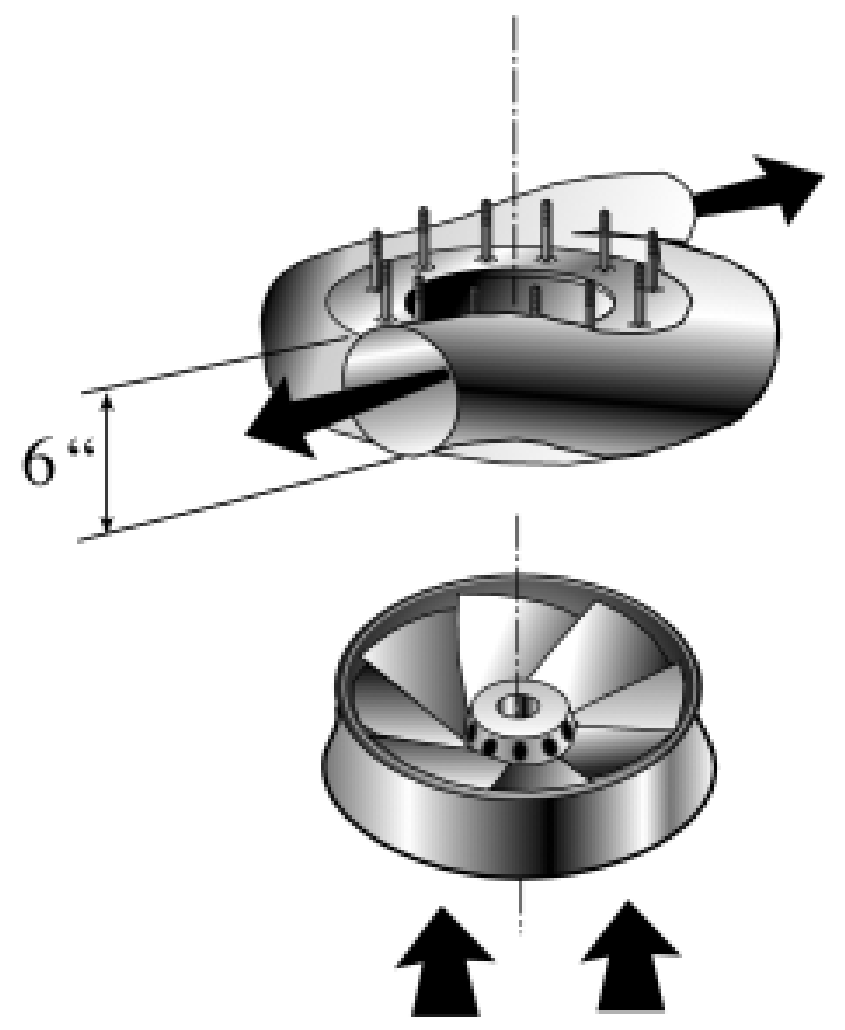

Figure 2.2. Example Baseline Pump (Lawrence Pump) with Top Injection Nozzles (lower part of figure shows pump impellers)

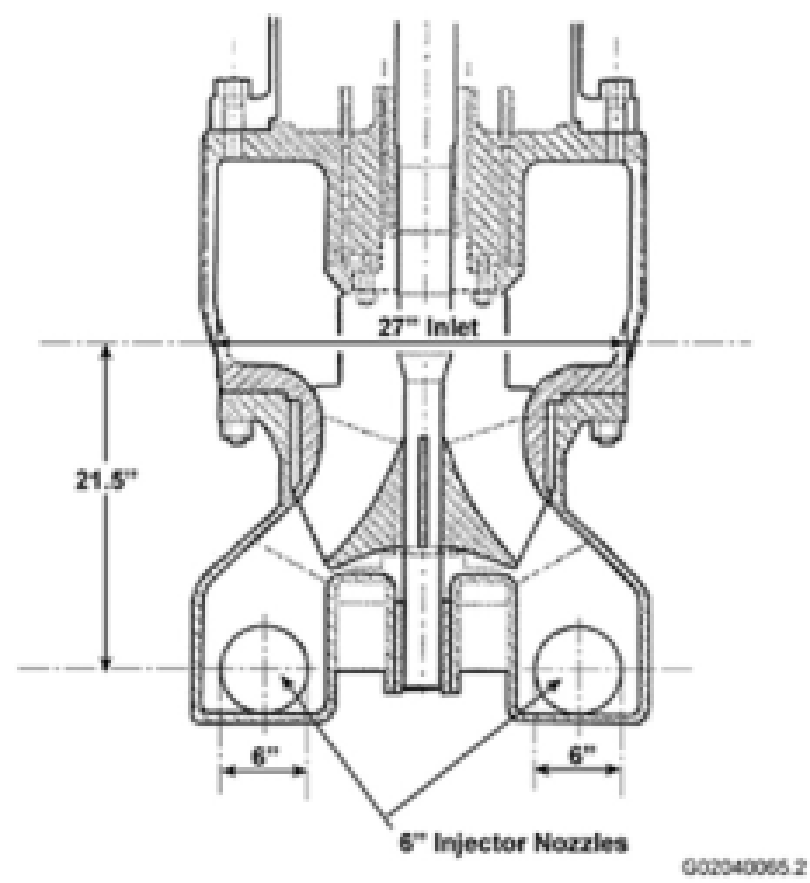

Figure 2.3. Example Alternative Pump (Sulzer Pump) with Bottom Injection Nozzles 
We selected eight pump levels, as shown in Table 2.1. Level 1 is the baseline pump position with the intake at the bottom and injection nozzles at the top. Levels 2 through 8 are for the alternative pump with the injection nozzle at the bottom and the intake at the top of the pump. Level 2 has the same injection nozzle position as the baseline pump, but the intake is at the top; thus, this case is considered the reference level of the alternative pump. Level 8 has the injection nozzle position above the baseline case (Level 1). We used the cylindrical coordinates for this modeling and made the model injection nozzle's cross-sectional area the same as the six-inch$(0.15-\mathrm{m}-)$ round nozzle openings of actual mixer pumps. Thus, the jets in this study have the same velocities and the cross-sectional areas at the nozzle exits as those of the baseline (Lawrence) and alternative (Sulzer) pumps.

Table 2.1. Pump Injection Nozzle and Intake Elevation Levels

\begin{tabular}{|c|c|c|c|c|c|c|c|c|c|}
\hline \multicolumn{2}{|c|}{$\begin{array}{l}\text { Height above tank bottom, } \\
\text { inches }\end{array}$} & $\begin{array}{c}\text { Level } \\
1\end{array}$ & $\begin{array}{c}\text { Level } \\
2\end{array}$ & $\begin{array}{l}\text { Level } \\
3\end{array}$ & $\begin{array}{c}\text { Level } \\
\quad 4\end{array}$ & $\begin{array}{c}\text { Level } \\
5\end{array}$ & $\begin{array}{l}\text { Level } \\
6\end{array}$ & $\begin{array}{l}\text { Level } \\
7\end{array}$ & $\begin{array}{l}\text { Level } \\
8\end{array}$ \\
\hline \multirow[t]{2}{*}{ Injection nozzle } & Centerline & 18.6 & 18.6 & 1.67 & 3.13 & 4.58 & 6.25 & 7.91 & 34.4 \\
\hline & & 16.9 & 16.9 & 0 & 1.46 & 2.91 & 4.58 & 6.25 & 32.7 \\
\hline \multicolumn{2}{|c|}{ Pump intake } & 7 & 40.1 & 23.1 & 24.6 & 26.0 & 27.7 & 29.4 & 55.9 \\
\hline
\end{tabular}

For all eight level position cases, we assigned sludge thicknesses of 22 inches $(0.56 \mathrm{~m})$ and 125 inches $(3.17 \mathrm{~m})$ to cover sludge thickness conditions greater and smaller than the AZ-102 sludge thickness of 35 inches $(0.89 \mathrm{~m})$. For all cases, we filled the model tank with supernatant liquid to bring the total waste height to 346 inches $(8.79 \mathrm{~m})$, which is basically the same as that of AZ-102 (345 in. or $8.76 \mathrm{~m}$ ).

\subsection{Model Setup}

There are 16 combinations of eight pump elevations and two sludge thicknesses. Because it would take up to a few months of CPU time to simulate sludge erosion by two rotating pumps to final quasi-equilibrium conditions, we adapted the following two-step approach:

Step 1: Simulate all 16 cases with two opposing, fixed-direction jets injected from a single, non-rotating mixer pump placed at the center of the tank (see Figure 1.1 for the pump position). The purpose of this effort was to select several of these 16 cases for a more detailed evaluation with the rotating pumps under Step 2. The models of Step 1 inject two $60-\mathrm{ft} / \mathrm{sec}(18.3-\mathrm{m})$ jets, one directed at 3 o'clock and the other at 9 o'clock. Based on symmetry, the actually simulated domains of these models are a quarter of the full tank. We refer them as "non-rotating mixer pump models" in this report.

Step 2: Conduct sludge erosion modeling with four rotating jets injected by two off-center rotating mixer pumps (see Figure 2.4, baseline pump with top injection nozzles, for the pump positions) for several cases selected from Step 1. The models in Step 2 inject two $60-\mathrm{ft} / \mathrm{sec}(18.3-\mathrm{m})$ jets $\left(180^{\circ}\right.$ from one another) from each of two rotating mixer pumps. Because these pumps are $22 \mathrm{ft}(6.7 \mathrm{~m})$ from tank center on opposite 


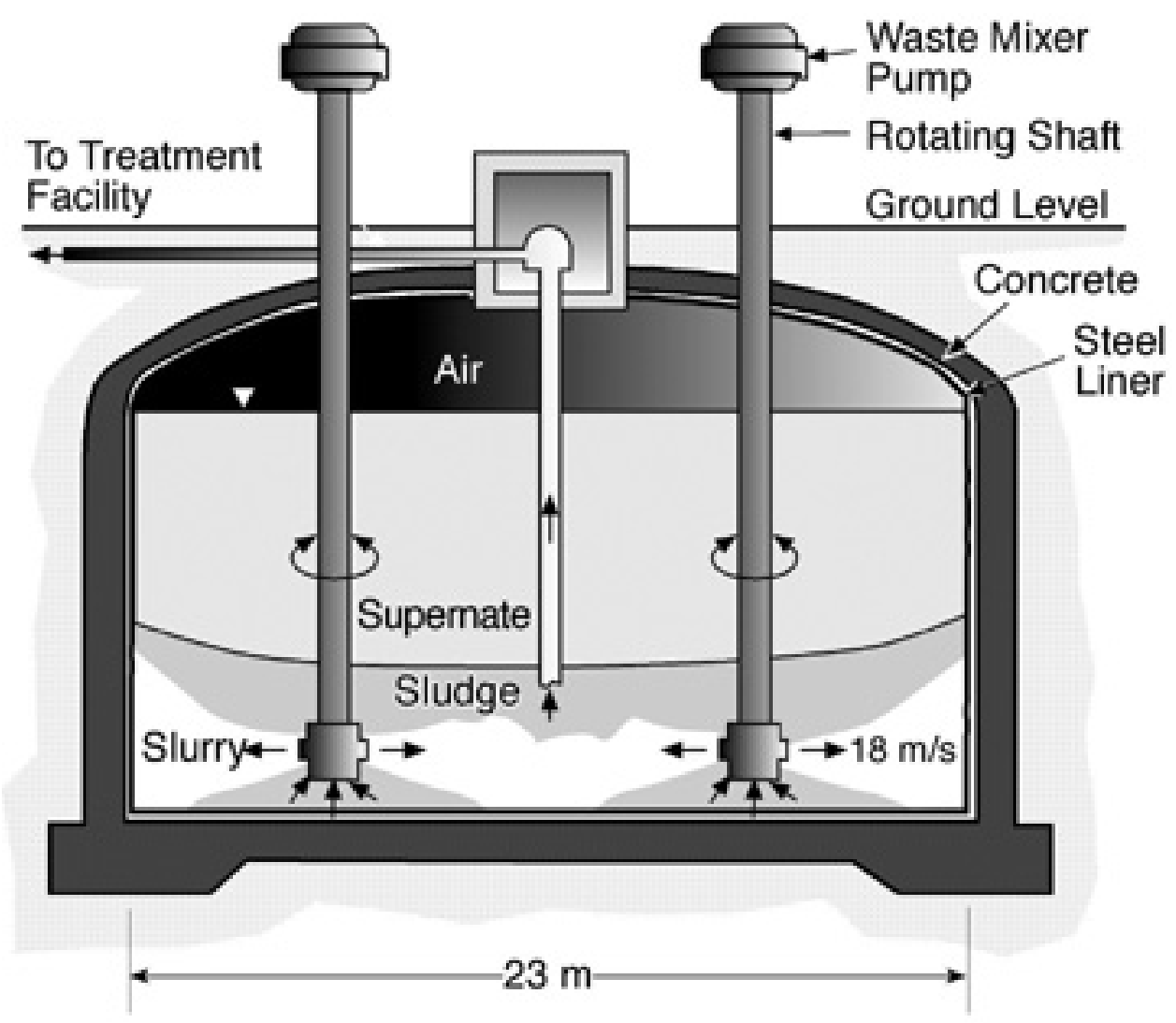

G02040065.1

Figure 2.4. Double-Shell Tanks with Two Rotating Mixer Pumps

sides of the tank and rotate at $0.2 \mathrm{rpm}$ in a synchronized mode, we simulated the right half of tank based on symmetry. We refer to them as "rotating mixer pump models" in this report.

We applied the time-dependent, three-dimensional TEMPEST code (Trent and Eyler 1993; Onishi and Trent 1999) to these rotating and non-rotating mixer pump models. 


\subsection{Non-Rotating Mixer Pump Model Results}

Under Step 1 evaluation, there are 16 cases covering the eight different pump inlet and injection positions shown in Table 2.1 and two sludge thicknesses of $125 \mathrm{in}$. $(3.17 \mathrm{~m})$ and $22 \mathrm{in}$. $(0.56 \mathrm{~m})$ with non-rotating mixer pump models. These cases are shown in Table 3.1.

Table 3.1. Sixteen Cases under Step 1 Evaluation

\begin{tabular}{|c|c|c|c|}
\hline \multirow[b]{3}{*}{ Cases } & \multicolumn{2}{|c|}{ Pump Positions } & \multirow[b]{3}{*}{$\begin{array}{c}\text { Sludge } \\
\text { Thickness } \\
\text { (in.) }\end{array}$} \\
\hline & \multicolumn{2}{|c|}{ Levels } & \\
\hline & $\begin{array}{c}\text { Injection above } \\
\text { Tank Bottom } \\
\text { (in.) }\end{array}$ & $\begin{array}{c}\text { Inlet above } \\
\text { Tank Bottom } \\
\text { (in.) } \\
\end{array}$ & \\
\hline \multirow{2}{*}{1} & \multicolumn{2}{|c|}{ Level 1} & \multirow{2}{*}{125} \\
\hline & 16.9 & 7 & \\
\hline \multirow{2}{*}{2} & \multicolumn{2}{|c|}{ Level 1} & \multirow{2}{*}{22} \\
\hline & 16.9 & 7 & \\
\hline \multirow{2}{*}{3} & \multicolumn{2}{|c|}{ Level 2} & \multirow{2}{*}{125} \\
\hline & 16.9 & 40.1 & \\
\hline \multirow{2}{*}{4} & \multicolumn{2}{|c|}{ Level 2} & \multirow{2}{*}{22} \\
\hline & 16.9 & 40.1 & \\
\hline \multirow{2}{*}{5} & \multicolumn{2}{|c|}{ Level 3} & \multirow[t]{2}{*}{125} \\
\hline & 0 & 23.1 & \\
\hline \multirow{2}{*}{6} & \multicolumn{2}{|c|}{ Level 4} & \multirow[t]{2}{*}{125} \\
\hline & 1.46 & 24.6 & \\
\hline \multirow{2}{*}{7} & \multicolumn{2}{|c|}{ Level 5} & \multirow[t]{2}{*}{125} \\
\hline & 2.91 & 26.0 & \\
\hline \multirow{2}{*}{8} & \multicolumn{2}{|c|}{ Level 6} & \multirow{2}{*}{125} \\
\hline & 4.58 & 27.7 & \\
\hline \multirow{2}{*}{9} & \multicolumn{2}{|c|}{ Level 7} & 125 \\
\hline & 6.25 & 29.4 & \\
\hline 10 & & & 125 \\
\hline 10 & 32.7 & 55.9 & 125 \\
\hline 11 & & & 22 \\
\hline 11 & 0 & 23.1 & 22 \\
\hline 12 & & & 22 \\
\hline 12 & 1.46 & 24.6 & \\
\hline 13 & & & 22 \\
\hline 13 & 2.91 & 26.0 & 22 \\
\hline & & & \\
\hline 14 & 4.58 & 27.7 & 22 \\
\hline 15 & & & 22 \\
\hline $1 J$ & 6.25 & 29.4 & 22 \\
\hline 16 & & & 22 \\
\hline 10 & 32.7 & 55.9 & \\
\hline
\end{tabular}


For each case, we applied the TEMPEST computer code (Trent and Eyler 1993; Onishi and Trent 1999) to the non-rotating mixer pump models. The simulations used the varying time steps of several milliseconds automatically selected based on various computational stability criteria built into the computer code and ran until the pump jet mixing simulation reached final steadystate erosion conditions. These runs reached this stage by 20 simulation minutes. Those simulation results are presented in this section.

\subsection{Mixing Performance Comparison of Pumps with Bottom or Top Intake}

Cases 1 and 2 (see Table 3.1) are baseline pump cases with 125-inch- (3.17-m-) and 22-inch(0.56-m-) thick sludges, respectively. Cases 3 and 4 are their corresponding reference cases for the alternative pump with these two sludge thicknesses. All these cases have the injection nozzles at the same elevation above the tank bottom. As stated previously, the baseline pump has the intake at the bottom, while the alternative pump has its intake at the top.

Figure 3.1 presents initial horizontal and vertical distributions of the velocity and solid concentrations of this quarter-tank non-rotating mixer pump model for Case 1. The horizontal distributions shown in the upper plot were at the jet nozzle elevation showing one of the two non-rotating jets whose center is directed along the 3 o'clock position. The vertical distribution shown in the lower plot is a cutoff along the 3 o'clock vertical plane. The figure shows the 125inch- (3.17-m-) thick sludge and 222-inch- (5.638-m-) thick supernatant liquid layer, totaling 346 inches $(8.788 \mathrm{~m})$ of waste in this tank. It also shows the positions of a non-rotating pump, its intake, and a nozzle injecting a $60-\mathrm{ft} / \mathrm{sec}(18.3-\mathrm{m} / \mathrm{s})$ jet into the sludge layer. As stated previously, the baseline pump withdraws the waste near the tank bottom and injects it back into the tank through the injection nozzle at $60 \mathrm{ft} / \mathrm{sec}(18.3 \mathrm{~m} / \mathrm{s})$. As shown in Figure 3.1, the sludge just around the pump was initially diluted, as is expected during the actual mixer pump operation, to ease pump startup.

The explanations are similar for both upper and lower plots of Figure 3.1, so we will describe mostly the lower plot. The tank boundary is indicated in this plot by the solid line, and the presence of the velocity vector indicates that its location is within the tank. The solids concentration within the sludge layer is 0.31 volume fraction (or 31 vol\%). The initial solids concentration in the supernatant liquid layer was assigned a small value $(0.001 \mathrm{vol} \%)$ rather than zero to handle the settling velocity of the solids for all solid concentrations. The top of this lower plot shows the time ( 0 simulation second). The left side of the figure describes which vertical plane it is showing (in this case the r-z plane at $\mathrm{I}=2$, which is oriented at the 3 o'clock position), and an area of plot coverage on this vertical plane (in this case, $\mathrm{J}=1$ to 42 , indicating the entire horizontal direction from the pump center to $37.5 \mathrm{ft}(11.5 \mathrm{~m})$, and $\mathrm{K}=1$ to 34 , indicating the vertical direction from the tank bottom to the waste surface at $8.788 \mathrm{~m}$ ). [The corresponding description of the upper plot is, " $\mathrm{r}-\mathrm{x}$ plane at $\mathrm{K}=16, \mathrm{~J}=2$ to $41, \mathrm{I}=2$ to 18 ," indicating that the plane is horizontal plane $16(\mathrm{~K}=16)$ containing the injection nozzle elevation (16.9 inch or $0.43 \mathrm{~m}$ ) and the plot covering the entire simulation area (the radial distance from $\mathrm{J}=2$ to $\mathrm{J}=41$ and $\mathrm{I}=2$ to 18 , which covers the entire $90^{\circ}$ area).] The left side of the lower plot also shows solid concentrations (expressed in volume fractions) represented by lines 1 through 10 . 

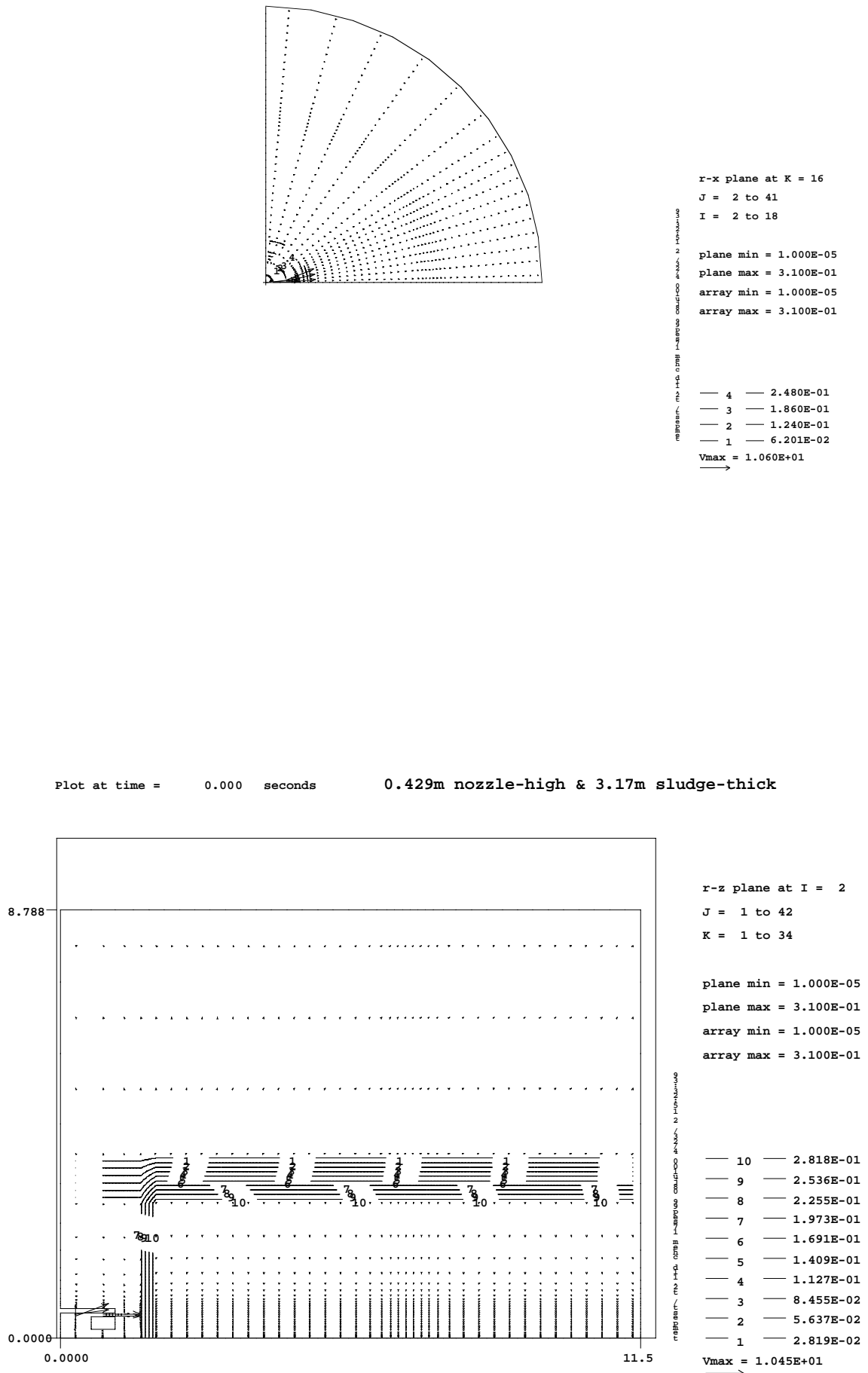

Figure 3.1. Case 1 (baseline pump with 3.17-m sludge): Initial Horizontal and Vertical Distributions of Velocity and Tank Waste 
Plane min and max indicate the minimum and maximum values (solid volume fractions of $1.0 \times 10^{-5}$ (or $0.001 \mathrm{vol} \%$ ) and 0.31 (or $31 \mathrm{vol} \%$ ), respectively, in this case) within the plotted plane, while array min and max indicate the minimum and maximum values (solid volume fractions of $1.0 \times 10^{-5}$ (or $0.001 \mathrm{vol} \%$ ) and 0.31 (or $31 \mathrm{vol} \%$ ), respectively, in this case) encountered within the entire tank simulation area. At the bottom left, the maximum velocity on this vertical plane is shown (in this case $10.45 \mathrm{~m} / \mathrm{s}$ with its corresponding scale length). All velocity magnitude in this plot is scaled to this magnitude. Note that the jet velocity at the nozzle exit was designated as $60 \mathrm{ft} / \mathrm{sec}(18.3 \mathrm{~m} / \mathrm{s})$ in this study. The maximum velocity of 10.45 $\mathrm{m} / \mathrm{s}$ listed in this figure is the velocity within the nozzle, not at the nozzle exit, and that it increases to the final velocity within a few seconds.

The predicted horizontal (the upper plot) and vertical (the lower plot) distributions of the velocity and solid volume fraction for Case 1 after reaching the final erosion state (20 simulation minutes) are shown in Figure 3.2. This figure shows that only some portion of the sludge was mobilized and mixed with the overlying liquid waste along the jet centerline. The jet removed the sludge within a narrow horizontal spread even at the pump jet elevation level (see the upper plot). We used the predicted results on the vertical plane ( $\mathrm{I}=2)$ containing the pump injection nozzle for this assessment, because the mixer pump would be rotated in the actual waste retrieval operation, and the erosion achieved along the jet centerline would be expected to occur along all other vertical planes. Predicted results of Case 2 with the thin sludge layer of 22 inch $(0.56 \mathrm{~m})$ are shown in Figure 3.3. Because the sludge is very thin in this case, the pump jet is only skimming the sludge surface and leaves a relatively large amount of the sludge undisturbed on the tank bottom.

Predicted horizontal and vertical distributions of the velocity and solid concentration at 20 simulation minutes for Cases 3 and 4 (reference cases for the alternative pump) are shown in Figures 3.4 and 3.5. These cases correspond to Cases 1 and 2 for the alternative pump with the top inlet and bottom injection nozzle configurations. Comparisons of Cases 1 and 3 (Figures 3.2 and 3.4) and Cases 2 and 4 (Figures 3.3 and 3.5) indicate they are very similar. Both the baseline and alternative pumps eroded $17.2 \%$ of the original sludge along the jet plane (3 o'clock plane) for the 125-inch sludge (Cases 1 and 3), while they eroded 4.9 and $5.8 \%$ of the sludge along this vertical plane $(\mathrm{I}=2)$ for Cases 2 and 4 . Thus these two pumps can mobilize very similar amounts of solids, although the alternative pump eroded slightly $(0.9 \%)$ more for the thin sludge condition.

The concept of the effective cleaning radius (ECR) was used in the past to express the sludge erosion amount (Powell et al. 1995a,b). The ECR is defined as the equivalent radius of erosion area whose volume corresponds to the total sludge amount eroded by the pump jet. With the predicted sludge erosion amount, we determined the corresponding ECR for these four cases. These ECR values are the same [15.6 ft $(4.75 \mathrm{~m})]$ for Cases 1 and 3, while the ECRs for Cases 2 and 4 are $8.3 \mathrm{ft}(2.53 \mathrm{~m})$ and $9.0 \mathrm{ft}(2.74 \mathrm{~m})$, respectively. 
Plot at time $=20.000$ minutes $\quad 0.429 \mathrm{~m}$ nozzle-high $\& 3.17 \mathrm{~m}$ sludge-thick

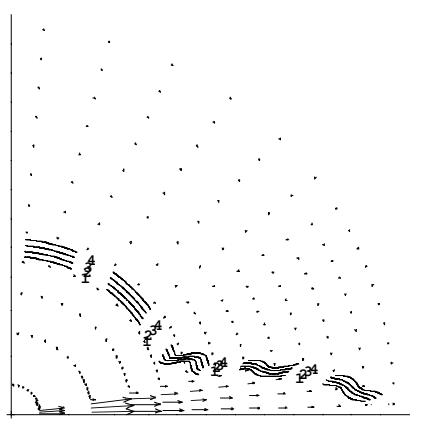

$-\mathrm{x}$ plane at $\mathrm{K}=1$ $J=2$ to 13

$I=2$ to 18

plane $\min =5.240 \mathrm{E}-03$ $\mathrm{plane} \max =3.100 \mathrm{E}-01$

array $\min =4.211 \mathrm{E}-03$ array $\max =3.100 \mathrm{E}-01$

s.

$-4-2.488 \mathrm{E}-01$ - $3-1.877 \mathrm{E}-01$ $-2-1.265 \mathrm{E}-01$ $V \max =1.572 \mathrm{E}+01$

Plot at time $=20.000$ minutes $\quad 0.429 \mathrm{~m}$ nozzle-high \& $3.17 \mathrm{~m}$ sludge-thick

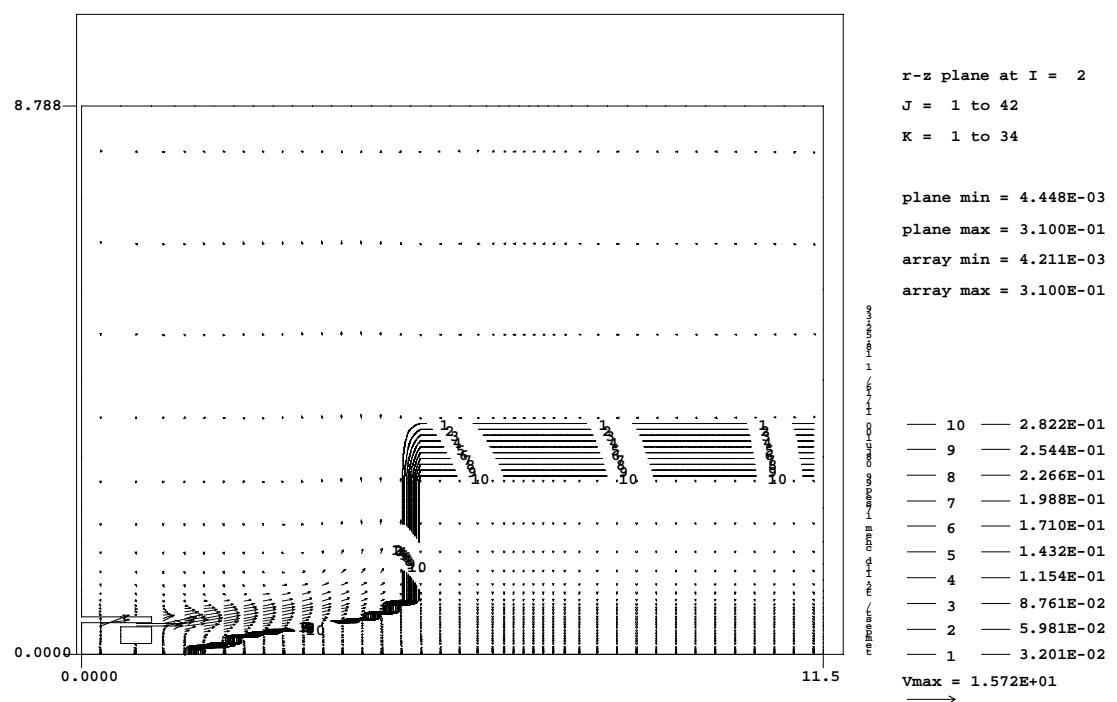

Figure 3.2. Case 1(baseline pump with 3.17-m sludge): Predicted Horizontal and Vertical Distributions of Velocity and Solid Volume Fraction at 20 Simulation Minutes 
Plot at time $=20.000$ minutes $\quad 0.429 \mathrm{~m}$ nozzle-high $\& 0.56 \mathrm{~m}$ sludge-thick



$\mathrm{r}-\mathrm{x}$ plane at $\mathrm{K}=16$

$\mathrm{J}=2$ to 14

$I=2$ to 18

Plane $\min =2.856 \mathrm{E}-04$

Plane $\max =3.100 \mathrm{E}-01$

array $\min =1.670 \mathrm{E}-04$

array $\max =3.100 \mathrm{E}-0$

$-4-2.480 \mathrm{E}-01$

$-3-1.861 \mathrm{E}-01$

$-2-1.241 \mathrm{E}-01$

$V \max =1.574 \mathrm{E}+0$

Plot at time $=20.000$ minutes $\quad 0.429 \mathrm{~m}$ nozzle-high $\& 0.56 \mathrm{~m}$ sludge-thick

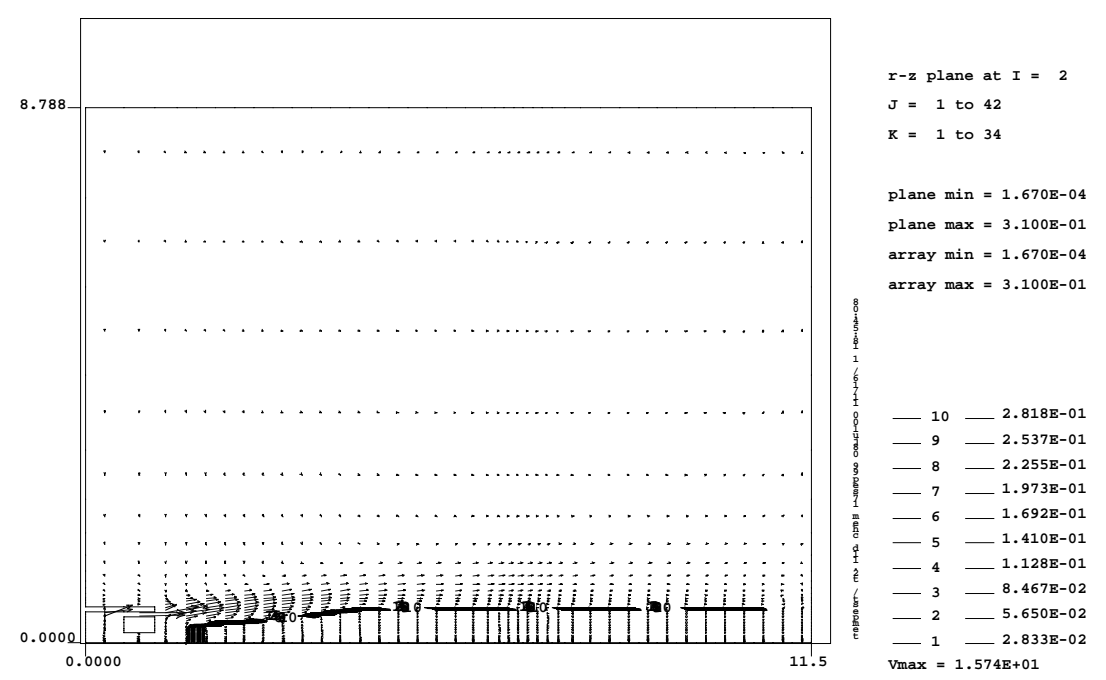

Figure 3.3. Case 2 (baseline pump with 0.56-m sludge): Predicted Horizontal and Vertical Distributions of Velocity and Solid Volume Fraction at 20 Simulation Minutes 
Plot at time $=20.000$ minutes $\quad 0.429 \mathrm{~m}$ nozzle-high $\& 3.17 \mathrm{~m}$ sludge-thick

qaid: Ju1 19, 2001; input $\rightarrow$ input. az102.90deg. lowest
title: AZ102, FIXED PUMP ANGLE (90deg model) Highest SLGbank
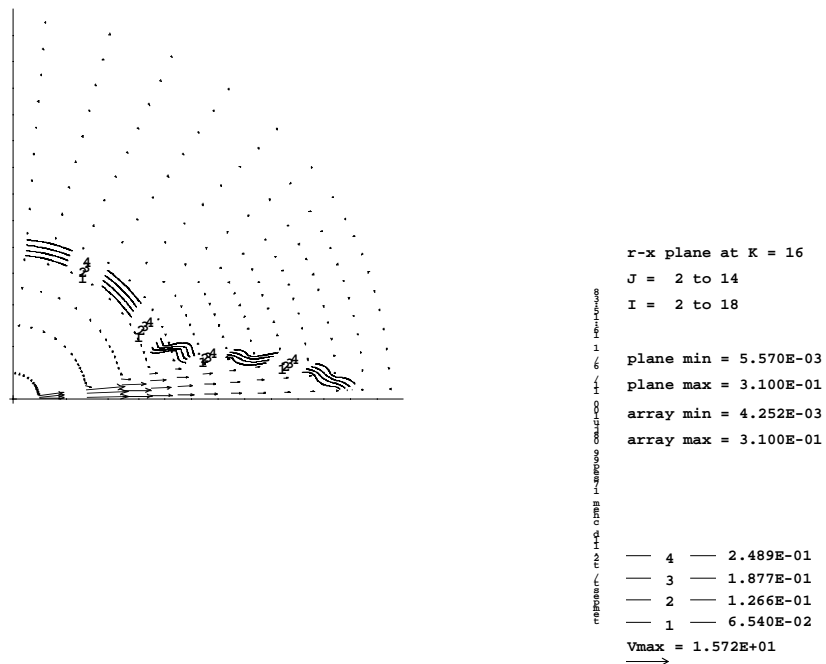

Plot at time $=20.000$ minutes $\quad 0.429 \mathrm{~m}$ nozzle-high \& $3.17 \mathrm{~m}$ sludge-thick

qaid: Jul 19, 2001; input $\rightarrow>$ input. az102.90deg. lowest
title: AZ102, FIXED PUMP ANGLE (90deg model) HighestSLGban

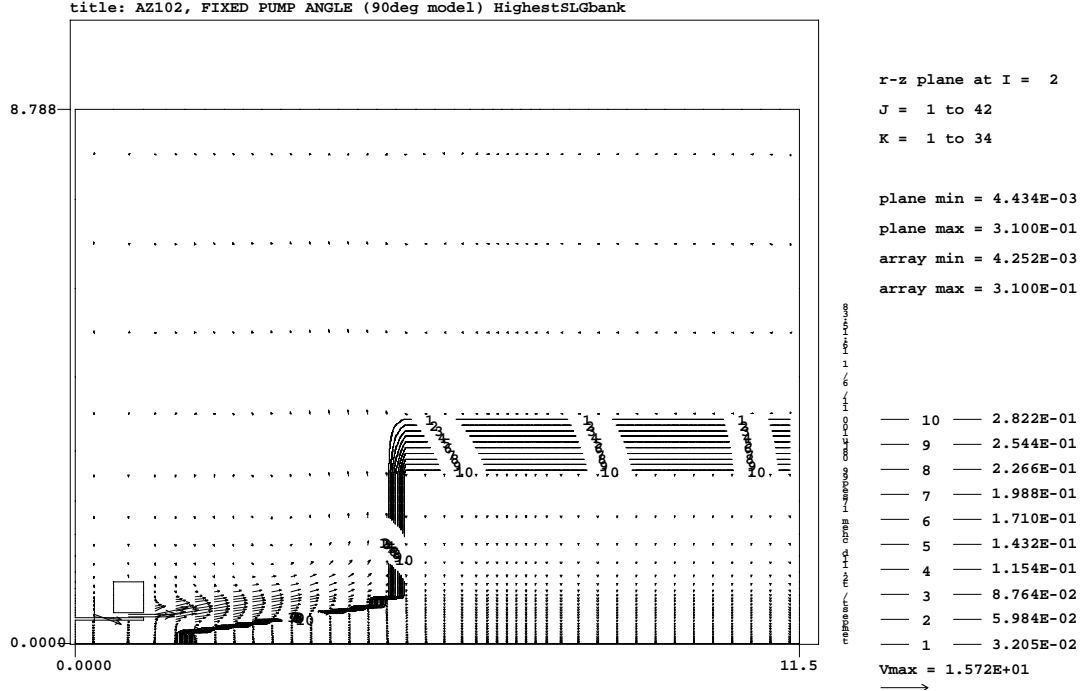

Figure 3.4. Case 3 (3.17-m sludge, alternative pump reference case): Predicted Horizontal and Vertical Distributions of Velocity and Solid Volume Fraction at 20 Simulation Minutes 
Plot at time $=20.000$ minutes $\quad 0.429 \mathrm{~m}$ nozzle-high $\& 0.56 \mathrm{~m}$ sludge-thick


Plot at time $=20.000$ minutes $\quad 0.429 \mathrm{~m}$ nozzle-high $\& 0.56 \mathrm{~m}$ sludge-thick

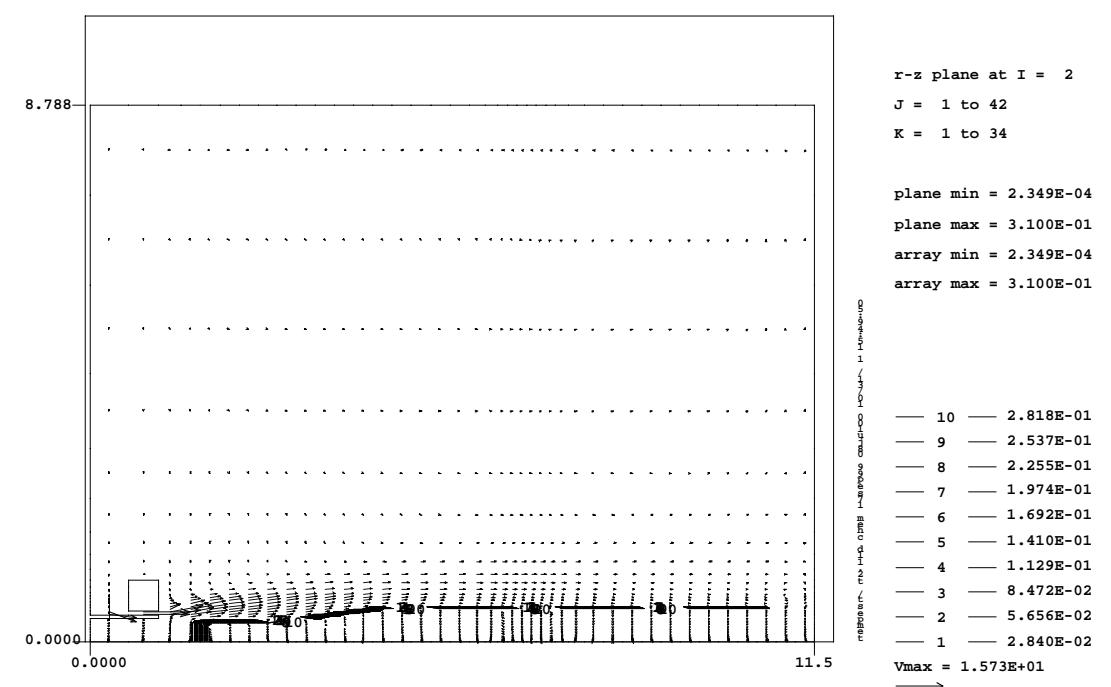

Figure 3.5. Case 4 (0.56-m sludge, alternative pump reference case): Predicted Horizontal Distributions of Velocity and Solid Volume Fraction at 20 Simulation Minutes 
We also converted these results of the single non-rotating mixer pump installed at the tank center to those of two rotating mixer pumps placed $20 \mathrm{ft}(6.1 \mathrm{~m})$ and $22 \mathrm{ft}(6.7 \mathrm{~m})$ off center by using these ECR values. Table 3.2 summarizes erosion amounts and ECRs of Cases 1 through 4 for a single pump placed at the tank center, as well as estimated values for two mixer pumps placed at $20 \mathrm{ft}(6.1 \mathrm{~m})$ and $22 \mathrm{ft}(6.7 \mathrm{~m})$ off center based on the results of the single non-rotating mixer pump simulations. As indicated in the table, the placement of the pump intake by itself (at the bottom or top of the pump) does not affect the pumps' erosion capability for the given pump injection nozzle elevation. For the thick, 125-inch (3.17-m) sludge (Cases 1 and 3), the baseline and alternative pumps eroded exactly the same solid amounts of sludge. The alternative pump eroded $1.9 \%$ more than the baseline pump in the thin 22-inch (0.56-m) sludge (Cases 2 and 4 ) by using two off-center pumps, but this difference is considered small.

Table 3.2. Summary of Baseline Lawrence and Corresponding Alternative Pump Cases

\begin{tabular}{|c|c|c|c|c|c|}
\hline $\begin{array}{c}\text { Case } \\
\text { number }\end{array}$ & $\begin{array}{c}\text { Sludge } \\
\text { thickness } \\
\text { (in.) }\end{array}$ & $\begin{array}{l}\text { Number of } \\
\text { pumps }\end{array}$ & $\begin{array}{l}\text { Pump location } \\
\text { from tank center } \\
(\mathrm{ft})\end{array}$ & $\begin{array}{l}\text { Erosion of the } \\
\text { total tank solid } \\
(\%)\end{array}$ & $\begin{array}{c}\text { Effective } \\
\text { cleaning radius } \\
(\mathrm{ft})\end{array}$ \\
\hline \multirow{3}{*}{1} & \multirow{3}{*}{125} & 1 & 0 & 17.2 & 15.6 \\
\hline & & \multirow{2}{*}{2} & 20 & 34.5 & 15.6 \\
\hline & & & 22 & 34.5 & 15.6 \\
\hline \multirow{3}{*}{2} & \multirow{3}{*}{22} & 1 & 0 & 4.9 & 8.3 \\
\hline & & \multirow{2}{*}{2} & 20 & 9.7 & 8.3 \\
\hline & & & 22 & 9.7 & 8.3 \\
\hline \multirow{3}{*}{3} & \multirow{3}{*}{125} & 1 & 0 & 17.2 & 15.6 \\
\hline & & \multirow{2}{*}{2} & 20 & 34.4 & 15.6 \\
\hline & & & 22 & 34.4 & 15.6 \\
\hline \multirow{3}{*}{4} & \multirow{3}{*}{22} & 1 & 0 & 5.8 & 9.0 \\
\hline & & \multirow{2}{*}{2} & 20 & 11.6 & 9.0 \\
\hline & & & 22 & 11.6 & 9.0 \\
\hline
\end{tabular}

\subsection{Optimal Elevation of Alternative Pump Placement}

An alternative pump has the injection nozzle at the pump bottom and the intake at the pump top (see Figure 2.3). Thus, the bottom of the injection nozzle is the bottom of the alternative pump. Placing a pump intake at the top enables the injection nozzles to be placed closer to the tank bottom. Some experiments of an air jet injected into air and a water jet injected into water (Rajaratnam and Subramanya 1968; Pani and Dash 1983) indicate that the horizontal jets injected near the solid bottom have faster centerline velocities at a given downstream distance; thus they may erode more sludge and saltcake than the jet placed farther away from the bottom. Furthermore, placing the intake at the top of the pump may withdraw less solids when the solid concentration is not vertically uniform, making it easier to start up a mixer pump.

We investigated how much more sludge, if any, the alternative pump can mobilize with the same pump jet discharge and velocity, and which pump elevation level can provide the optimal erosion capability of the alternative pump. We selected seven elevations of pump placement 
ranging from the bottom of the pump sitting on the tank bottom to 32.7 inch above the tank bottom (shown in Table 2.1 as Levels 2 through 8, which are all alternative pump cases). They correspond to Cases 3 through 16 shown in Table 3.1. Note that the jet injection elevation of the baseline pump (Cases 1 and 2) and the corresponding alternative pump's reference cases (Cases 3 and 4) are between Levels 7 and 8. Cases 3 and 4 are discussed in Section 3.1, and the results of Cases 5 through 16, plus an overall evaluation based on the Non-Rotating Mixer Pump Model results, are discussed in this section.

Predicted velocity and solid concentrations at 20 simulation minutes for Cases 5 through 10, all having the thick, 125-inch (3.17-m) sludge, are shown in Figures 3.6 through 3.11. These results clearly reveal that placing the pump injection levels right on or very close to the tank bottom enables the mixer pump to mobilize significantly more sludge. Also, as the injection level becomes higher, the pump jet slides over the sludge without eroding it all the way to the tank bottom.

Predicted velocity and solid concentrations at 20 simulation minutes for Cases 11 through 16, all having the thin 22-inch $(0.56-\mathrm{m})$ thick sludge, are shown in Figures 3.12 through 3.17. Similar to the cases with the 125-inch- (3.17-m-) thick sludge, these results with thin sludge also indicate that placing the pump injection levels right on or very close to the tank bottom makes the mixer pump erode more sludge. As the injection level becomes higher, the pump jet slides over the sludge without eroding it to the tank bottom. As expected, when the injection level is above the sludge layer (Case 16 with Figure 3.17), no sludge is eroded by the jet.

Table 3.3 summarizes sludge erosion amounts based on all 16 baseline and alternative cases of the non-rotating pump model results. Variations of solid erosion volumes versus the nozzle injection heights (the pump bottom elevations for the alternative pump cases) are shown in Figure 3.18 for the 125-inch (3.17-m) thick sludge cases (Cases 1, 3 and 5 through 10). Figure 3.19 shows the erosion volume percent normalized by the erosion amount of the alternative pump's reference case (Case 3: alternative pump), which is the same as that of the baseline pump case (Case 1). Corresponding plots for the thin 22-inch (0.56-m) sludge cases (Cases 2, 4, and 11 through 16) are shown in Figures 3.20 and 3.21, respectively. Figure 3.21 shows the erosion percent normalized by the erosion volume of the alternative reference case (Case 4). 
Plot at time $=20.000$ minutes $\quad 0 \mathrm{~m}$ nozzle-high $\& 3.17 \mathrm{~m}$ sludge-thick

qaid: Ju1 19, 2001; input $\rightarrow$ input.az102.90deg.tankbottom
title: AZ102, FIXED PUMP ANGLE (90deg mode1) HighestSLGbank
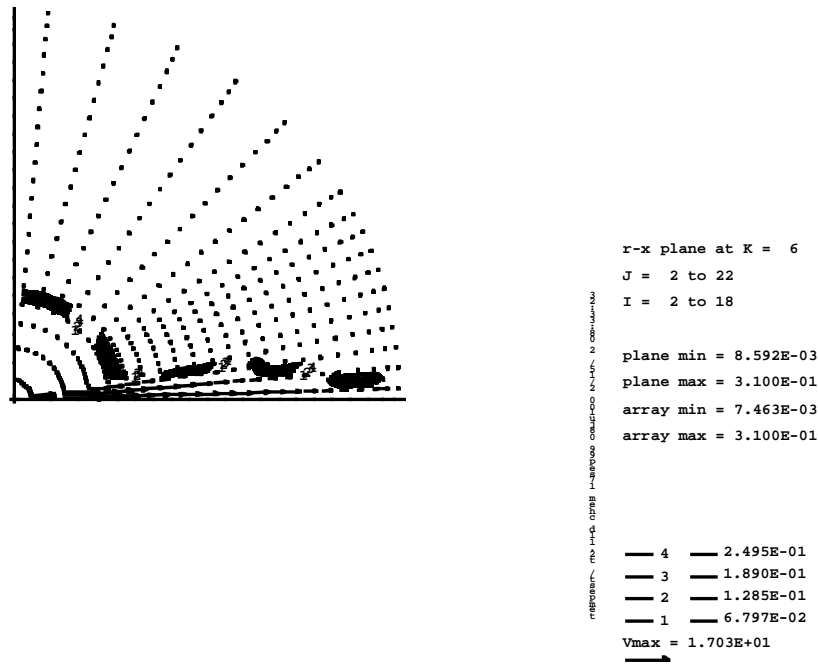

Plot at time $=20.000$ minutes $\quad 0 \mathrm{~m}$ nozzle-high $\& 3.17 \mathrm{~m}$ sludge-thick

qaid: Jul 19, 2001; input $\rightarrow$ input.az102.90deg.tankbottom
title: AZ102, FIXED PUMP ANGLE (90deg model) HighestSLGbank

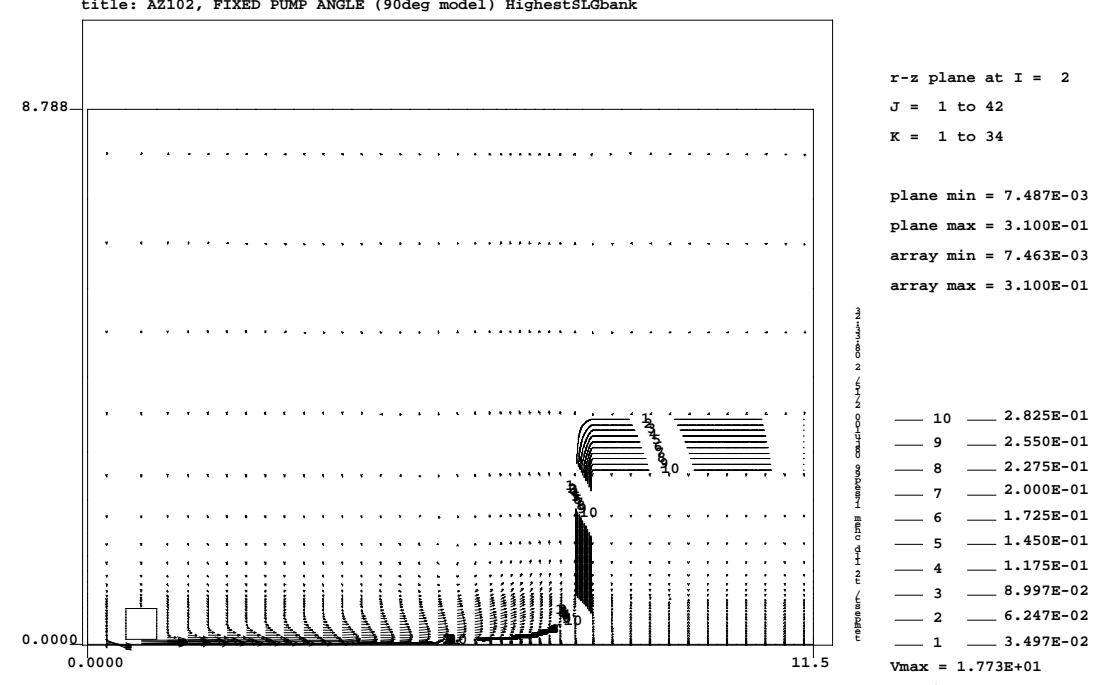

Figure 3.6. Case 5 (alternative pump on tank bottom, 3.17-m sludge): Predicted Horizontal and Vertical Distributions of Velocity and Solid Volume Fraction at 20 Simulation Minutes 


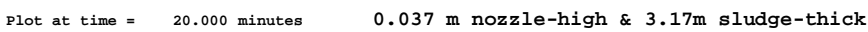
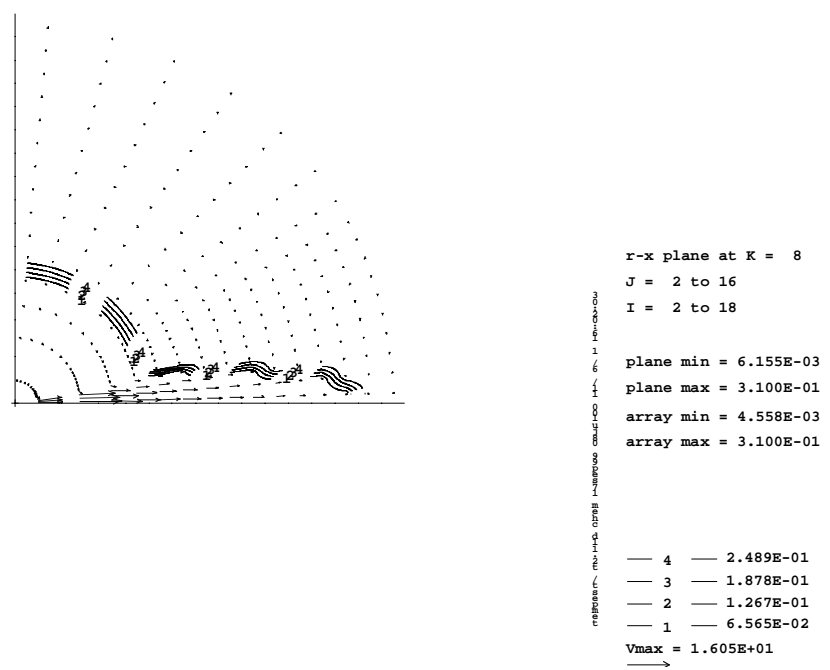

Plot at time $=20.000$ minutes $\quad 0.037 \mathrm{~m}$ nozzle-high \& $3.17 \mathrm{~m}$ sludge-thick



Figure 3.7. Case 6 (alternative pump $0.037 \mathrm{~m}$ above tank bottom, $3.17-\mathrm{m}$ sludge): Predicted Horizontal and Vertical Distributions of Velocity and Solid Volume Fraction at 20 Simulation Minutes 
Plot at time $=20.000$ minutes $\quad 0.074 \mathrm{~m}$ nozzle-high $\& 3.17 \mathrm{~m}$ sludge-thick

qaid: Ju1 19, 2001; input $\rightarrow$ input. az102.90deg. lowest
title: AZ102, FIXED PUMP ANGLE (90deg mode1) HighestSLGbank

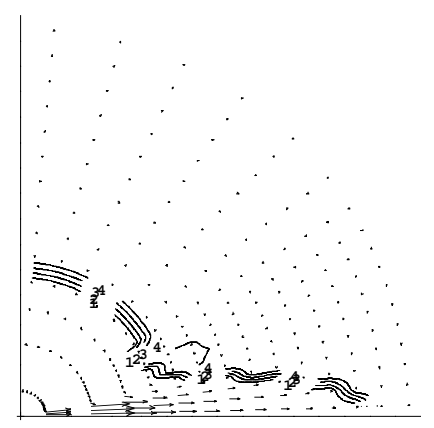

$\mathrm{r}-\mathrm{x}$ plane at $\mathrm{K}=8$

$J=2$ to 15

$I=2$ to 18

plane $\min =6.031 \mathrm{E}-03$

$\mathrm{plane} \max =3.100 \mathrm{E}-01$

array $\min =4.313 \mathrm{E}-03$

array $\max =3.100 \mathrm{E}-0$

旁

$-4-2.489 \mathrm{E}-01$

$-3-1.8778-1.06$

$-2-1.266 \mathrm{E}-01$

- 1 - $6.545 \mathrm{E}-02$

$\operatorname{Vmax}=1.570 \mathrm{E}+01$



Figure 3.8. Case 7 (alternative pump $0.074 \mathrm{~m}$ above tank bottom, 3.17-m sludge): Predicted Horizontal and Vertical Distributions of Velocity and Solid Volume Fraction at 20 Simulation Minutes 
Plot at time $=20.000$ minutes $\quad 0.116 \mathrm{~m}$ nozzle-high \& $3.17 \mathrm{~m}$ sludge-thick

qaid: Jul 19, 2001; input $\rightarrow$ input. az102.90deg. 1 owest
tit1e: AZ102, FIXED PUMP ANGLE (90deg mode1) Highest


Plot at time $=20.000$ minutes $\quad 0.116 \mathrm{~m}$ nozzle-high \& $3.17 \mathrm{~m}$ sludge-thick

qaid: Jul 19, $2001 ;$ input $\rightarrow$ input. az102.90deg. lowest
tit1e: AZ102, FIXED PUMP ANGLE (90deg mode1) HighestSLGbank

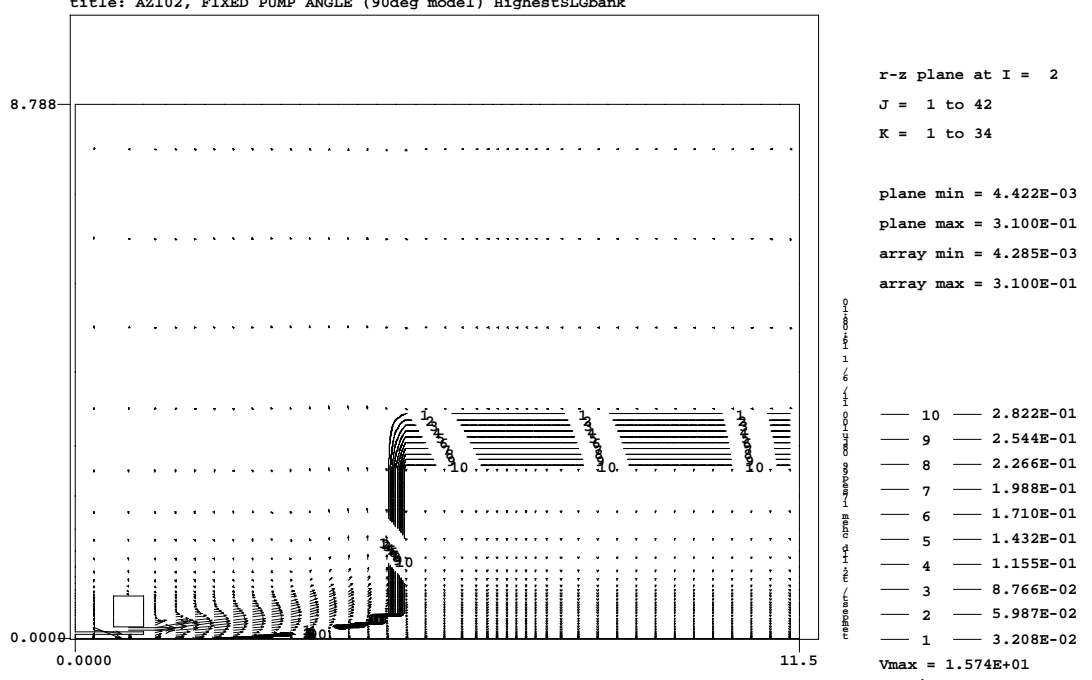

Figure 3.9. Case 8 (alternative pump $0.116 \mathrm{~m}$ above tank bottom, 3.17 -m sludge): Predicted Horizontal and Vertical Distributions of Velocity and Solid Volume Fraction at 20 Simulation Minutes 
Plot at time $=20.000$ minutes $\quad 0.159 \mathrm{~m}$ nozzle-high $\& 3.17 \mathrm{~m}$ sludge-thick qaid: Ju1 19, 2001; input $\rightarrow$ input.az102.90deg. lowest
title: AZ102, FIXED PUMP ANGLE (90deg mode1) Highest SLGbank


Plot at time $=20.000$ minutes $\quad 0.159 \mathrm{~m}$ nozzle-high $\& 3.17 \mathrm{~m}$ sludge-thick

qaid: Ju1 19, 2001; input $\rightarrow$ input. az102.90deg. lowest
title: AZ102, FIXED PUMP ANGLE (90deg mode1) HighestSLGb



$V \max =1.570 E+01$

Figure 3.10. Case 9 (alternative pump $0.159 \mathrm{~m}$ above tank bottom, 3.17-m sludge): Predicted Horizontal and Vertical Distributions of Velocity and Solid Volume Fraction at 20 Simulation Minutes 
Plot at time $=20.000$ minutes $\quad 0.831 \mathrm{~m}$ nozzle-high $\& 3.17 \mathrm{~m}$ sludge-thick

qaid: Jul 19, 2001; input $\rightarrow$ input. az102.90deg. 1 owest
tit1e: AZ102, FIXED PUMP ANGLE (90deg mode1) Highest

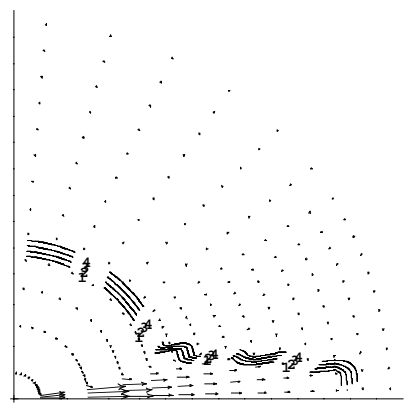

$\mathrm{r}-\mathrm{x}$ plane at $\mathrm{K}=25$

$\mathrm{J}=2$ to 14

$I=2$ to 18

plane $\min =4.504 \mathrm{E}-03$

plane $\max =3.100 \mathrm{E}-01$

array $\min =3.694 \mathrm{E}-03$

array max $=3.100 \mathrm{E}-01$

槅

$-4-2.487 \mathrm{E}-01$

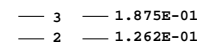

$-1-6.496 \mathrm{E}-02$

$\stackrel{\mathrm{max}}{\longrightarrow}=1.572 \mathrm{E}+01$

Plot at time $=20.000$ minutes $\quad 0.831 \mathrm{~m}$ nozzle-high \& $3.17 \mathrm{~m}$ sludge-thick

qaid: Jul 19, 2001; input $\rightarrow$ input. az102.90deg. lowest

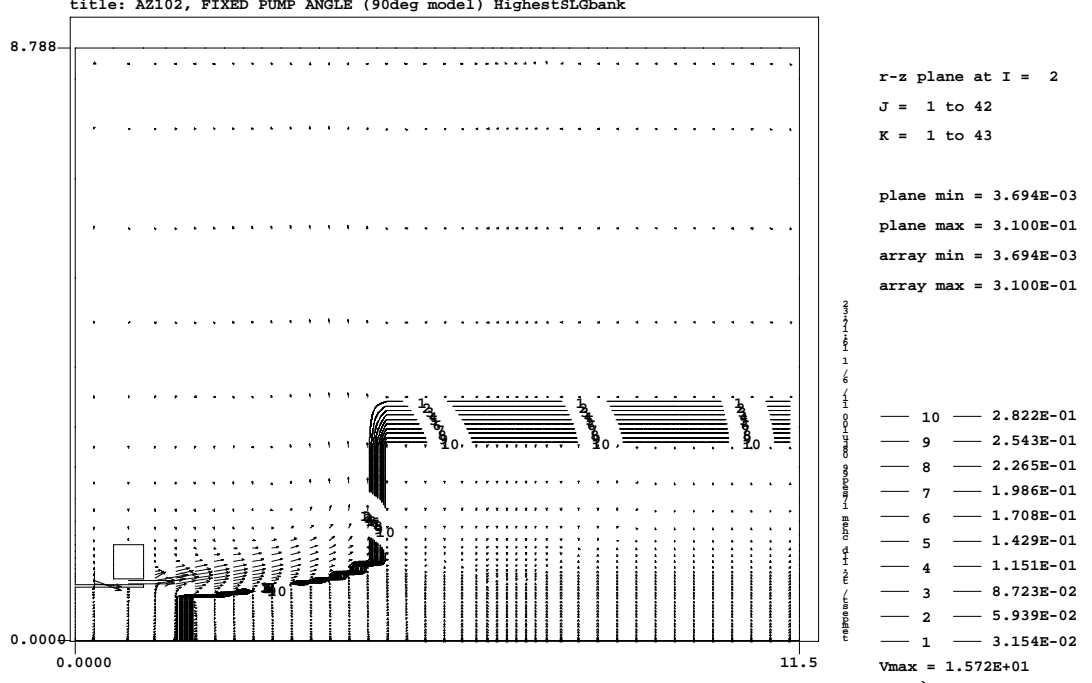

Figure 3.11. Case 10 (alternative pump $0.831 \mathrm{~m}$ above tank bottom, 3.17-m sludge): Predicted Horizontal and Vertical Distributions of Velocity and Solid Volume Fraction at 20 Simulation Minutes 
Plot at time $=20.000$ minutes $\quad 0 \mathrm{~m}$ nozzle-high $\& 0.59 \mathrm{~m}$ sludge-thick
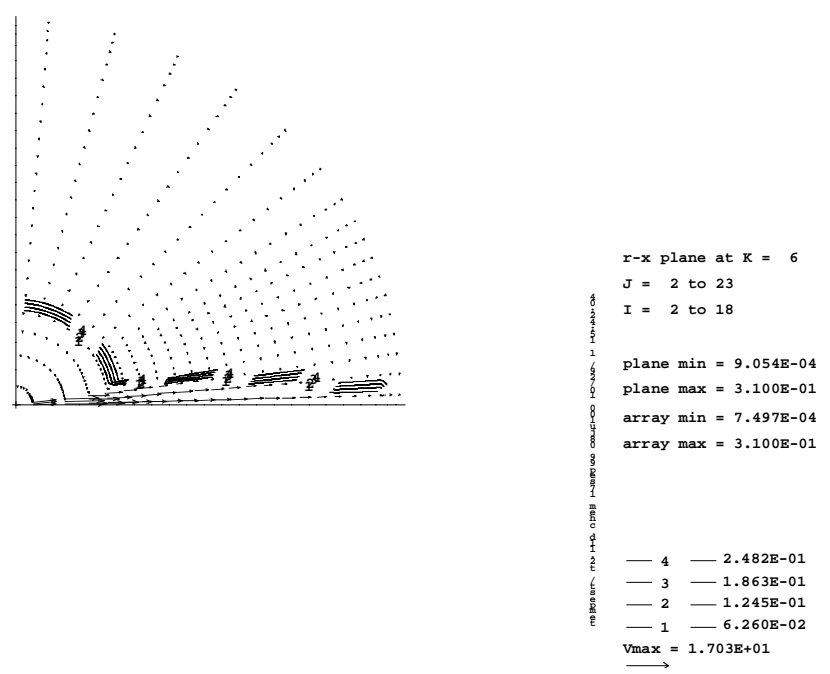

Plot at time $=20.000$ minutes $\quad 0 \mathrm{~m}$ nozzle-high $\& 0.59 \mathrm{~m}$ sludge-thick

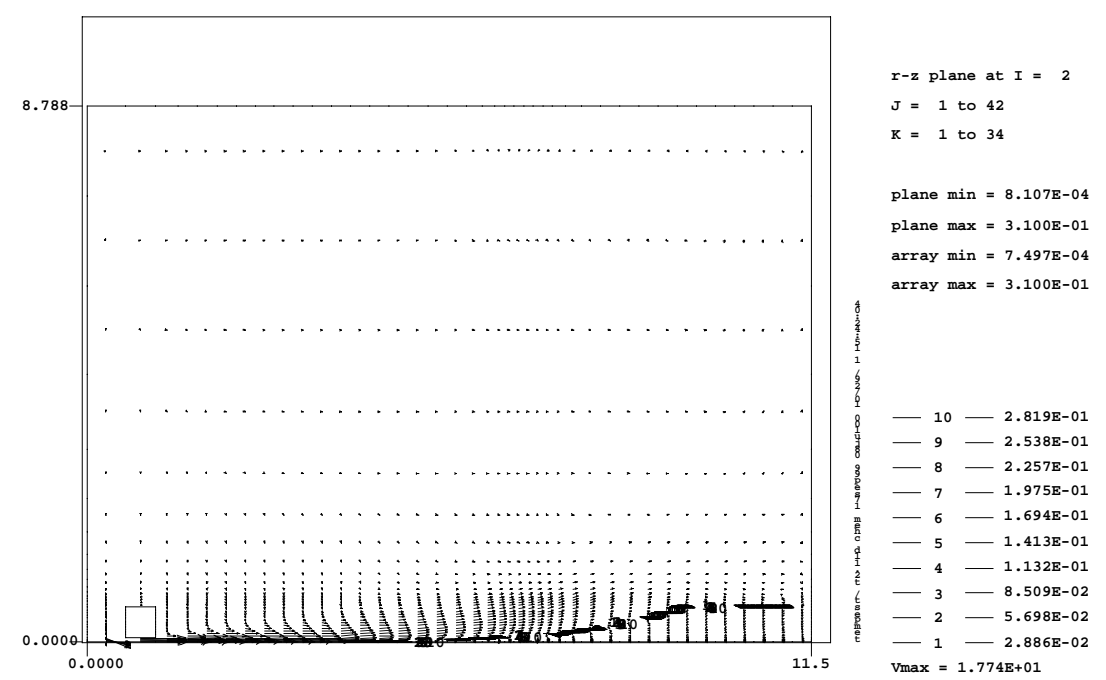

Figure 3.12. Case 11 (alternative pump at tank bottom, 0.56-m sludge): Predicted Horizontal and Vertical Distributions of Velocity and Solid Volume Fraction at 20 Simulation Minutes 
Plot at time $=20.000$ minutes $\quad 0.037 \mathrm{~m} \mathrm{nozzle-high} \& 0.56 \mathrm{~m}$ sludge-thick
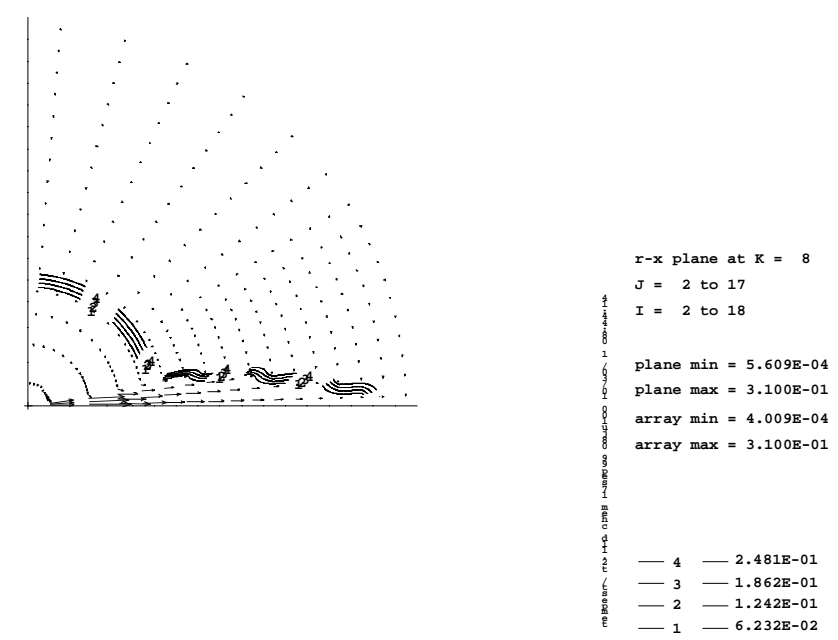

Plot at time $=20.000$ minutes $\quad 0.037 \mathrm{~m}$ nozzle-high $\& 0.56 \mathrm{~m}$ sludge-thick

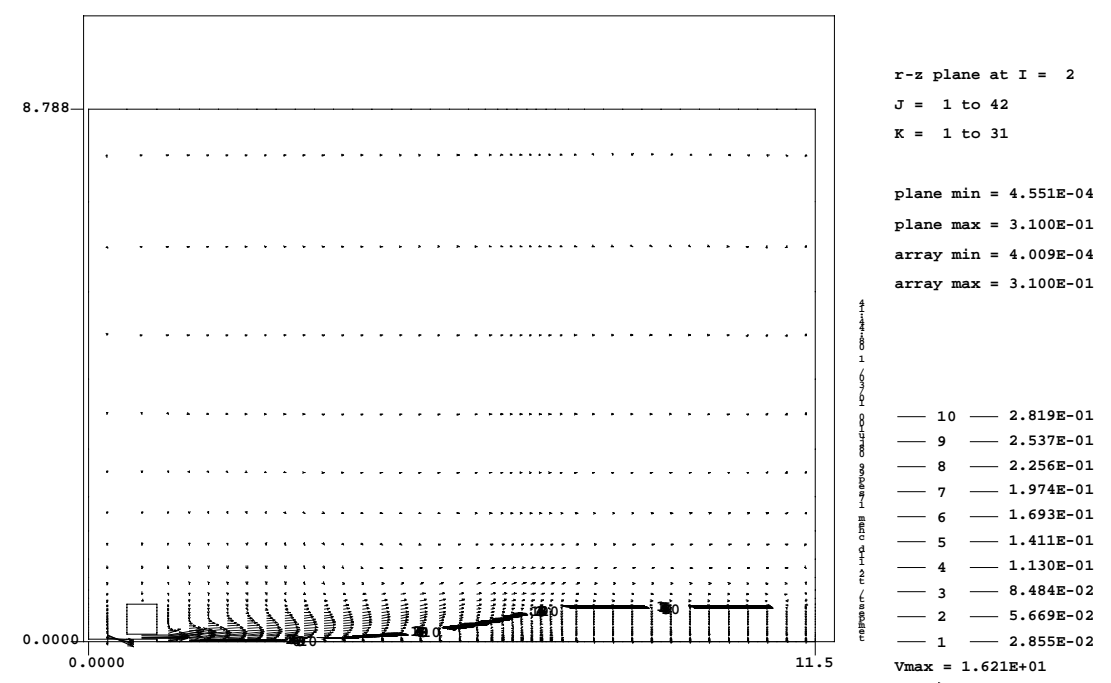

Figure 3.13. Case 12 (alternative pump $0.037 \mathrm{~m}$ above tank bottom, $0.56-\mathrm{m}$ sludge): Predicted Horizontal and Vertical Distributions of Velocity and Solid Volume Fraction at 20 Simulation Minutes 
Plot at time $=20.000$ minutes $\quad 0.074 \mathrm{~m}$ nozzle-high $\& 0.56 \mathrm{~m}$ sludge-thick
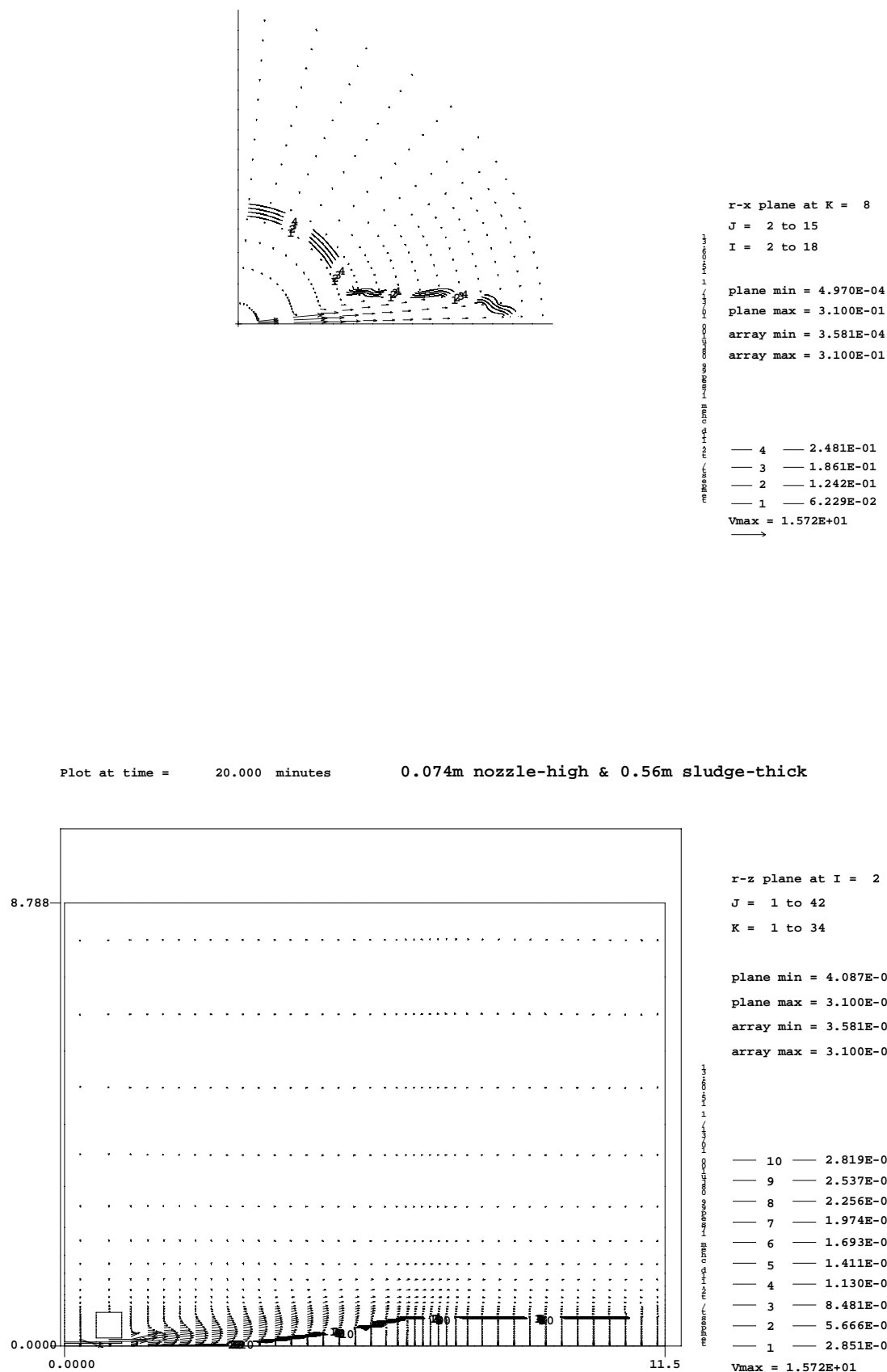

$x-z$ plane at $I=$

$\mathrm{K}=1$ to 34

plane $\min =4.087 \mathrm{E}-04$

plane $\max =3.100 \mathrm{E}-01$

array $\min =3.581 \mathrm{E}-04$

array $\max =3.100 \mathrm{E}-0$

$\frac{1}{3}$

$-10-2.819 \mathrm{E}-01$

$-9-2.537 \mathrm{E}-01$

- $8-2.256 \mathrm{E}-01$

$7-1.974 \mathrm{E}-01$

- $6-1.693 \mathrm{E}-01$

- $5-1.411 \mathrm{E}-0$

$-4-1.130 \mathrm{E}-0$

$4-8.481 \mathrm{E}-02$
$-3-5.666 \mathrm{E}-02$

- $1-2.851 \mathrm{E}-02$

$\mathrm{Vmax}=1.572 \mathrm{E}+01$

Figure 3.14. Case 13 (alternative pump $0.074 \mathrm{~m}$ above tank bottom in $0.56-\mathrm{m}$ sludge): Predicted Horizontal and Vertical Distributions of Velocity and Solid Volume Fraction at 20 Simulation Minutes 
Plot at time $=20.000$ minutes $\quad 0.116 \mathrm{~m}$ nozzle-high $\& 0.56 \mathrm{~m}$ sludge-thick



$\mathrm{r}-\mathrm{x}$ plane at $\mathrm{K}=9$

$J=2$ to 16

$I=2$ to 18

plane $\min =5.093 \mathrm{E}-04$ plane $\max =3.100 \mathrm{E}-01$ array $\min =3.740 \mathrm{E}-04$ array $\max =3.100 \mathrm{E}-01$$$
\text { s. }
$$$$
\text { 商 }
$$

$-4-2.481 \mathrm{E}-01$

$-3-862 \mathrm{E}-01$
$-3-1.242 \mathrm{E}-01$

${ }^{2}{ }^{2}{ }^{1.242 \mathrm{E}-01}$

$\mathrm{Vmax}=1.576 \mathrm{E}+01$

Plot at time $=20.000$ minutes $\quad 0.116 \mathrm{~m} \mathrm{nozzle-high} \mathrm{\&} 0.56 \mathrm{~m}$ sludge-thick

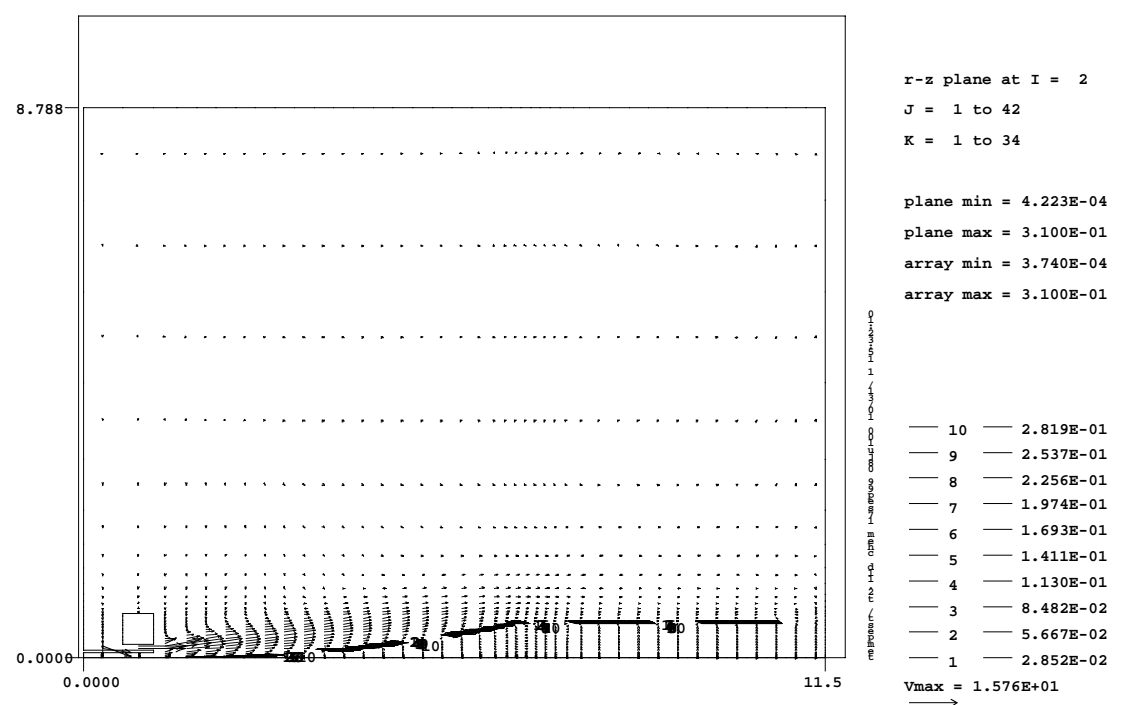

Figure 3.15. Case 14 (alternative pump $0.116 \mathrm{~m}$ above tank bottom, 0.56-m sludge): Predicted Horizontal and Vertical Distributions of Velocity and Solid Volume Fraction at 20 Simulation Minutes 
Plot at time $=20.000$ minutes $\quad 0.159 \mathrm{~m}$ nozzle-high $\& 0.56 \mathrm{~m}$ sludge-thick


Plot at time $=20.000$ minutes $\quad 0.159 \mathrm{~m}$ nozzle-high $\& 0.56 \mathrm{~m}$ sludge-thick

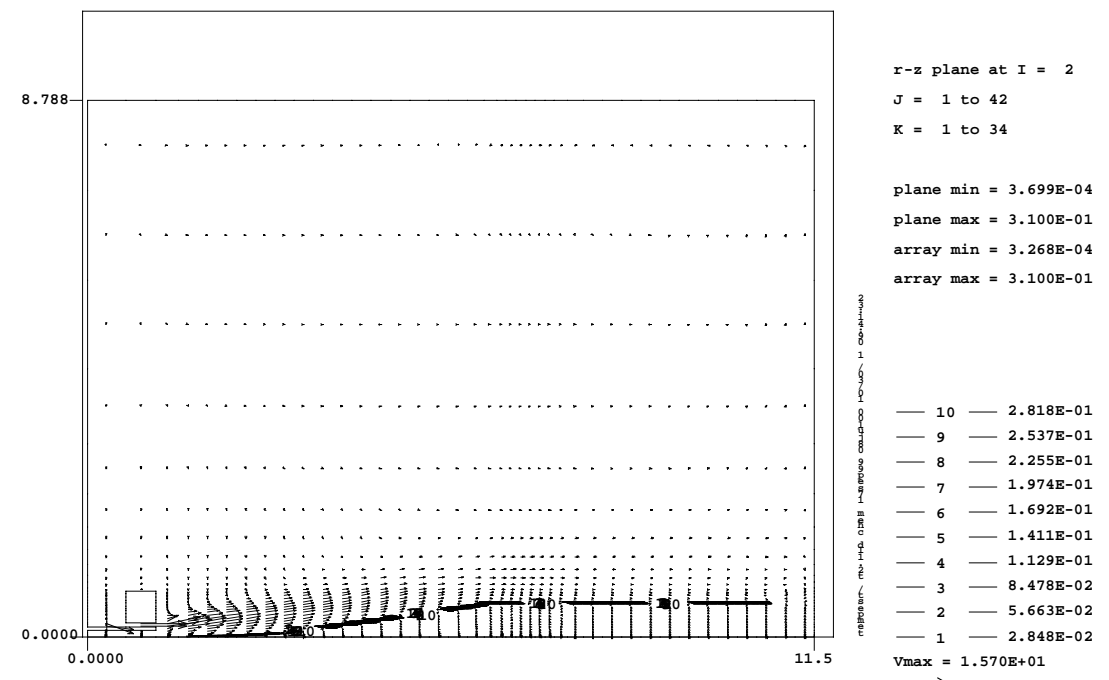

Figure 3.16. Case 15 (alternative pump $0.159 \mathrm{~m}$ above tank bottom, $0.56-\mathrm{m}$ sludge): Predicted Horizontal and Vertical Distributions of Velocity and Solid Volume Fraction at 20 Simulation Minutes 

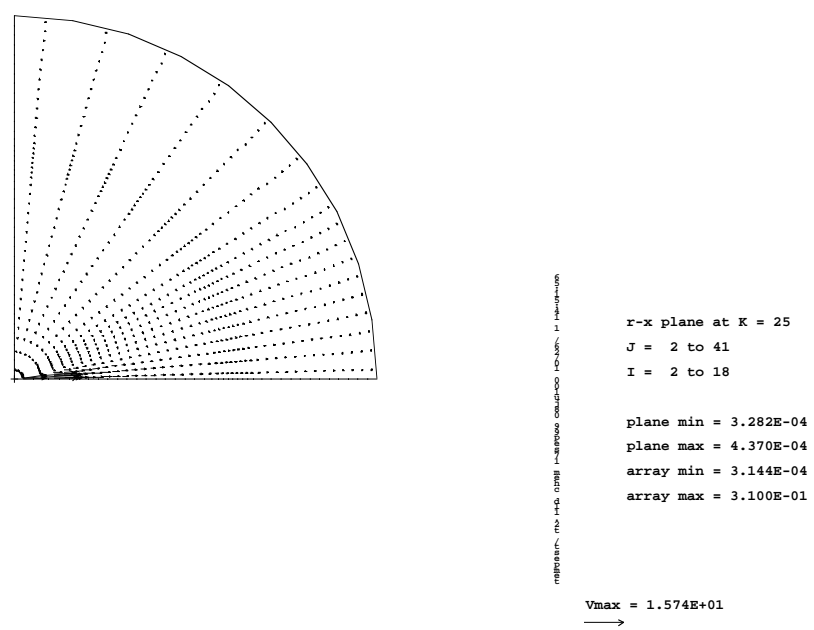

Plot at time $=20.000$ minutes $\quad 0.831 \mathrm{~m}$ nozzle-high $\& 0.56 \mathrm{~m}$ sludge-thick

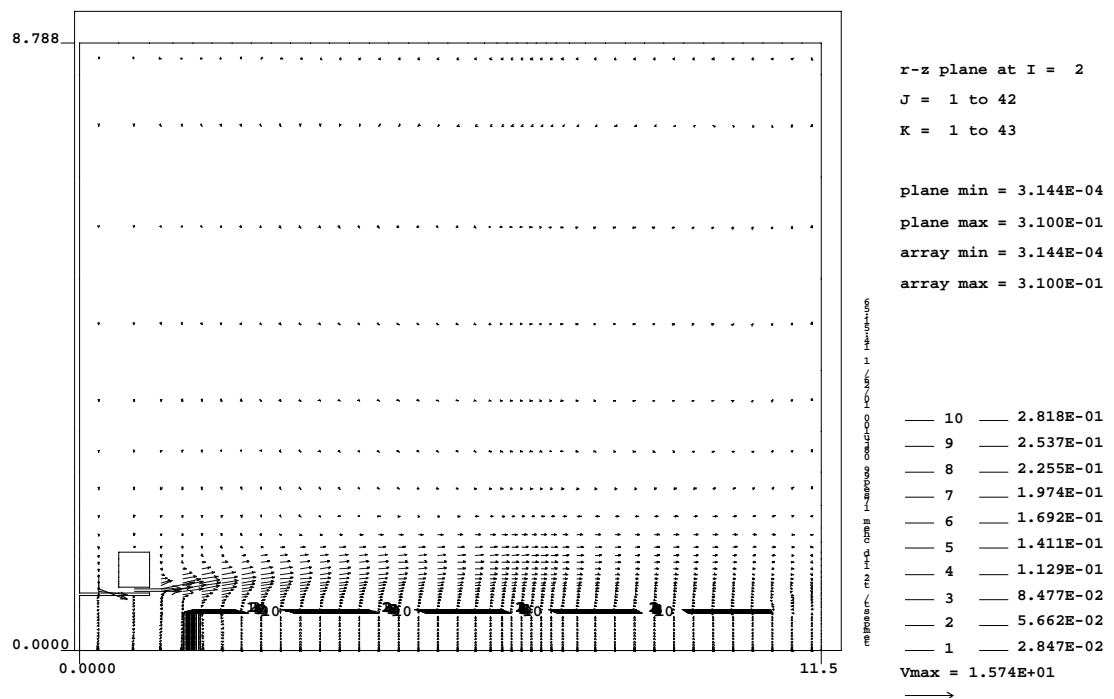

Figure 3.17. Case 16 (alternative pump $0.831 \mathrm{~m}$ above tank bottom over 0.56-m sludge): Predicted Horizontal and Vertical Distributions of Velocity and Solid Volume Fraction at 20 Simulation Minutes 
Table 3.3. Summary of Sludge Erosion Based on Non-Rotating Pump Model Results

\begin{tabular}{|c|c|c|c|c|c|}
\hline $\begin{array}{c}\text { Case } \\
\text { Number }\end{array}$ & $\begin{array}{c}\text { Sludge } \\
\text { Thickness } \\
\text { (in.) }\end{array}$ & $\begin{array}{l}\text { Number of } \\
\text { Pumps }\end{array}$ & $\begin{array}{c}\text { Pump Location } \\
\text { from Tank } \\
\text { Center } \\
\text { (ft) }\end{array}$ & $\begin{array}{l}\text { Erosion } \\
\quad(\%)\end{array}$ & $\begin{array}{c}\text { ECR } \\
(\mathbf{f t})\end{array}$ \\
\hline \multirow{3}{*}{1} & \multirow{3}{*}{125} & 1 & 0 & 17.2 & 15.6 \\
\hline & & \multirow{2}{*}{2} & 20 & 34.5 & 15.6 \\
\hline & & & 22 & 34.5 & 15.6 \\
\hline \multirow{3}{*}{2} & \multirow{3}{*}{22} & 1 & 0 & 4.9 & 8.3 \\
\hline & & \multirow{2}{*}{2} & 20 & 9.7 & 8.3 \\
\hline & & & 22 & 9.7 & 8.3 \\
\hline \multirow{3}{*}{3} & \multirow{3}{*}{125} & 1 & 0 & 17.2 & 15.6 \\
\hline & & \multirow{2}{*}{2} & 20 & 34.4 & 15.6 \\
\hline & & & 22 & 34.4 & 15.6 \\
\hline \multirow{3}{*}{4} & \multirow{3}{*}{22} & 1 & 0 & 5.8 & 9.0 \\
\hline & & \multirow{2}{*}{2} & 20 & 11.6 & 9.0 \\
\hline & & & 22 & 11.6 & 9.0 \\
\hline \multirow{3}{*}{5} & \multirow{3}{*}{125} & 1 & 0 & 45.5 & 25.3 \\
\hline & & \multirow{2}{*}{2} & 20 & 73.1 & 25.3 \\
\hline & & & 22 & 73.1 & 25.3 \\
\hline \multirow{3}{*}{6} & \multirow{3}{*}{125} & 1 & 0 & 24.0 & 18.4 \\
\hline & & \multirow{2}{*}{2} & 20 & 47.5 & 18.4 \\
\hline & & & 22 & 47.5 & 18.4 \\
\hline \multirow{3}{*}{7} & \multirow{3}{*}{125} & 1 & 0 & 19.2 & 16.4 \\
\hline & & \multirow{2}{*}{2} & 20 & 38.4 & 16.4 \\
\hline & & & 22 & 38.4 & 16.4 \\
\hline \multirow{3}{*}{8} & \multirow{3}{*}{125} & 1 & 0 & 19.0 & 16.4 \\
\hline & & \multirow{2}{*}{2} & 20 & 38.1 & 16.4 \\
\hline & & & 22 & 38.1 & 16.4 \\
\hline \multirow{3}{*}{9} & & 1 & 0 & 18.8 & 16.3 \\
\hline & 125 & 2 & 20 & 37.6 & 16.3 \\
\hline & & 2 & 22 & 37.6 & 16.3 \\
\hline & & 1 & 0 & 13.4 & 13.7 \\
\hline 10 & 125 & $?$ & 20 & 26.8 & 13.7 \\
\hline & & 2 & 22 & 26.8 & 13.7 \\
\hline & & 1 & 0 & 50.8 & 26.7 \\
\hline 11 & 22 & 2 & 20 & 77.1 & 26.7 \\
\hline & & 2 & 22 & 75.4 & 26.7 \\
\hline & & 1 & 0 & 26.1 & 19.2 \\
\hline 12 & 22 & 2 & 20 & 51.1 & 19.2 \\
\hline & & 2 & 22 & 48.8 & 19.2 \\
\hline & & 1 & 0 & 19.6 & 16.6 \\
\hline 13 & 22 & & 20 & 39.2 & 16.6 \\
\hline & & 2 & 22 & 38.7 & 16.6 \\
\hline & & 1 & 0 & $\begin{array}{ll}19.8 \\
\end{array}$ & 16.6 \\
\hline 14 & 22 & 2 & 20 & 39.5 & 16.6 \\
\hline & & 2 & 22 & 38.9 & 16.6 \\
\hline
\end{tabular}


Table 3.3. Summary of Sludge Erosion Based on Non-Rotating Pump Model Results

\begin{tabular}{|c|c|c|c|c|c||}
\hline \multirow{2}{*}{$\begin{array}{c}\text { Case } \\
\text { Number }\end{array}$} & $\begin{array}{c}\text { Sludge } \\
\text { Thickness } \\
\text { (in.) }\end{array}$ & $\begin{array}{c}\text { Number of } \\
\text { Pumps }\end{array}$ & $\begin{array}{c}\text { Pump Location } \\
\text { from Tank } \\
\text { Center } \\
\text { (ft) }\end{array}$ & $\begin{array}{c}\text { Erosion } \\
(\%)\end{array}$ & $\begin{array}{c}\text { ECR } \\
\text { (ft) }\end{array}$ \\
\hline \multirow{3}{*}{15} & \multirow{2}{*}{22} & 1 & 0 & 16.1 & 15.0 \\
\cline { 3 - 6 } & & 2 & 20 & 32.1 & 15.0 \\
\cline { 3 - 6 } & \multirow{2}{*}{16} & 1 & 22 & 32.1 & 15.0 \\
\cline { 3 - 6 } & 22 & 2 & 0 & 0 & 0 \\
\cline { 3 - 6 } & & 2 & 22 & 0 & 0 \\
\hline
\end{tabular}



Figure 3.18. Predicted Mobilized Sludge Volume Percent Compared with Initial Total Sludge Volume: Sludge Thickness 125 inches $(3.17 \mathrm{~m})$ 


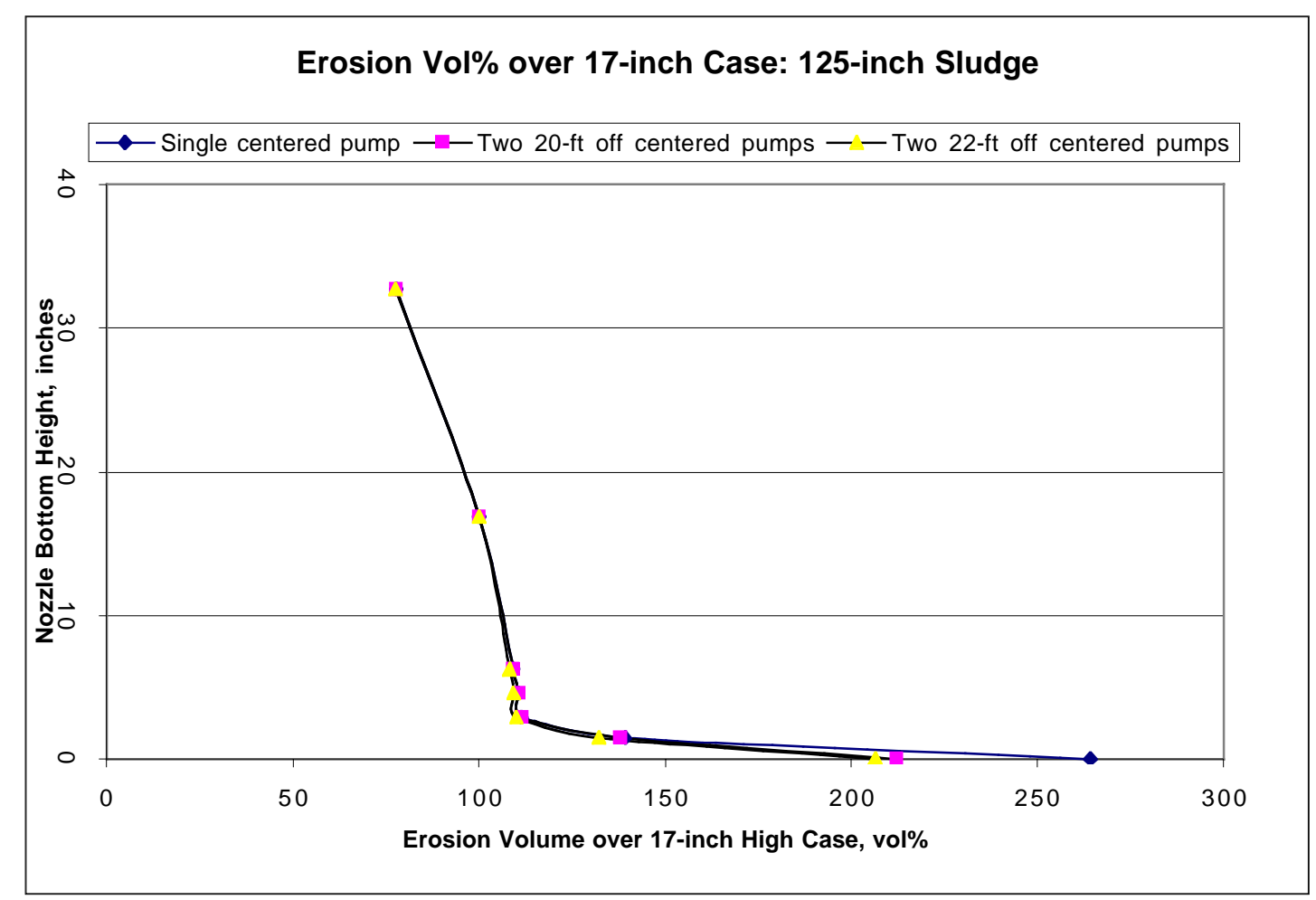

Figure 3.19. Predicted Vol\% of Eroded Sludge Normalized by Case 3 (alternative pump reference case): Sludge Thickness 125 inches $(3.17 \mathrm{~m})$



Figure 3.20. Predicted Mobilized Sludge Volume Percent Compared with Initial Total Sludge Volume for Sludge Thickness of 22 inches $(0.56 \mathrm{~m})$ 


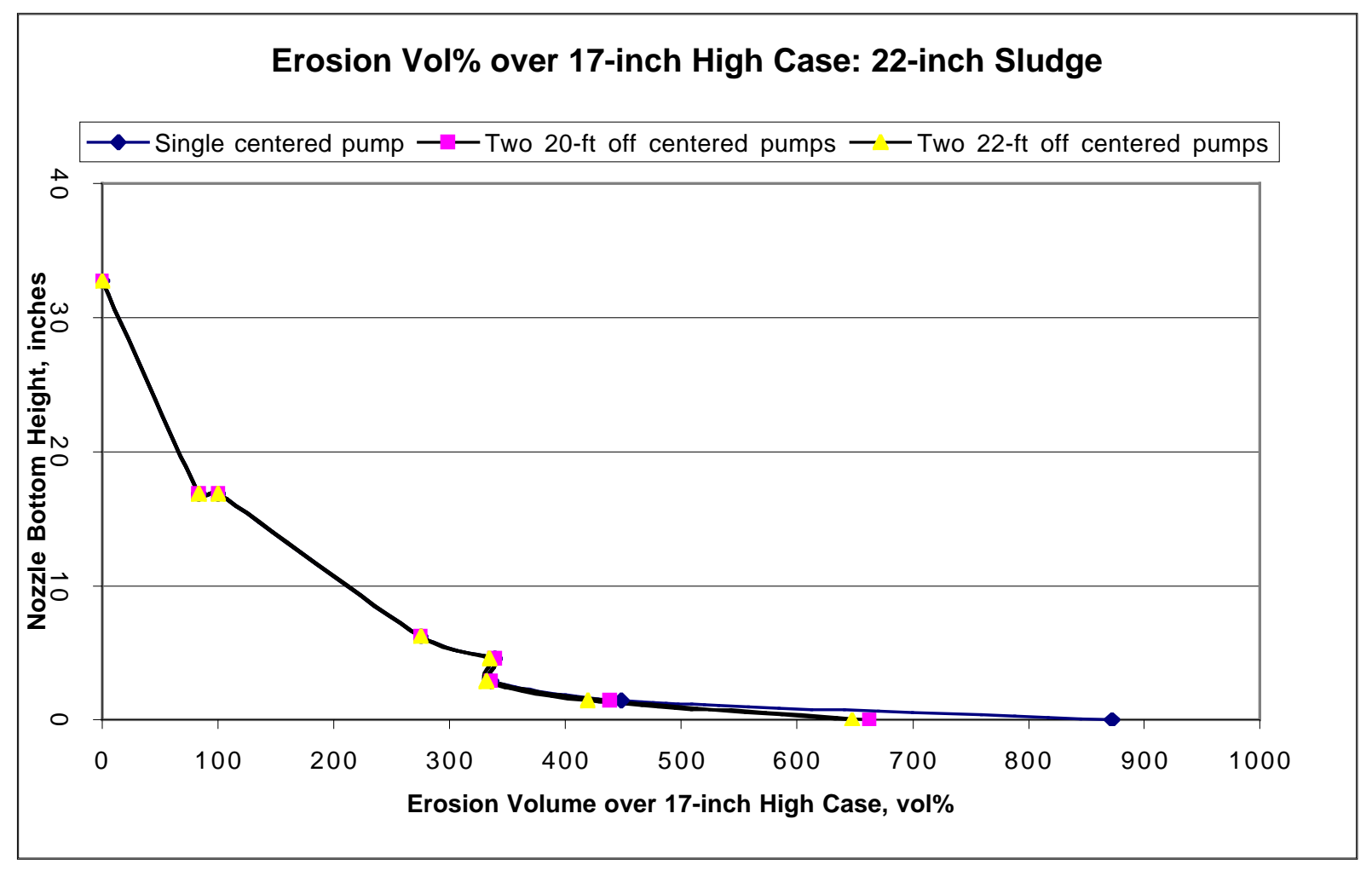

Figure 3.21. Vol\% of Eroded Sludge Normalized by Case 4 (alternative pump reference case): Sludge Thickness 22 inches $(0.56 \mathrm{~m})$

Figures 3.18 through 3.21 indicate that all cases with injection nozzle elevation lower than that of the baseline pump would produce more erosion of the sludge than the baseline pump case. When the alternative pump is placed above the baseline elevation (Cases 10 and 16), the pump will erode less sludge than the baseline case. The closer the injection elevation to the bottom of the tank, the greater the sludge erosion. When the pump injection nozzle is placed on the tank bottom, the pump will mobilize $200 \sim 900 \%$ more sludge than the pump that is 17 inches above the tank bottom. When the pump injection is 1.5 inches $(0.038 \mathrm{~m})$ above the tank bottom, it erodes $140 \sim 500 \%$ more sludge than the 17-inch injection case.

When the injection level is 3 to 6 inches $(0.076$ to $0.15 \mathrm{~m})$ above tank bottom, the amounts of sludge eroded are basically the same: the pump erodes $10 \sim 20 \%$ more sludge than the 17-inchinjection reference case. The similar erosion capabilities of the 3- to 6-inch (0.076- to 0.15-m) jet injection level cases may be explained as follows. As the jet is injected at or near the tank bottom, the tank bottom restricts the jet vertical spread (reduces entrainment of the surrounding, non-moving waste into the moving jet). The tank bottom also exerts friction on the jet, slowing its velocity. Thus, the jet near the tank bottom is subject to these two opposing wall effects created by the tank bottom. For jets injected 3 to 6 inches $(0.076$ to $0.15 \mathrm{~m})$ above the tank bottom, the combined impact of those two opposing effects may be almost the same at these three elevations, producing basically the same solid erosion capability. However, these three cases would erode more sludge than the reference case, as stated above. 
There may be some engineering difficulties in placing large 300-hp mixer pumps within approximately 6 inches $(0.15 \mathrm{~m})$ of the tank bottom. For example, the DST bottom is not absolutely flat. There is also a possibility of the mixer pumps hitting and damaging the tank bottom during the installation. Thus, we did not select any alternative pump cases with the pump within 1.5 inches $(0.038 \mathrm{~m})$ of the tank bottom for further evaluation. Instead, we selected the level of the bottom of the mixer pumps (the bottom of the injection nozzles) as 3 and 6 inches $(0.076$ and $0.15 \mathrm{~m})$, as well as reference Case 3 [16.9 inches $(0.43 \mathrm{~m})$ ], for further evaluation with the more realistic rotating mixer pump models. These cases are evaluated in Section 4. 


\subsection{Rotating Mixer Pump Model Results}

The non-rotating pump modeling identified the possibly realistic elevation of the pump injection nozzle bottom (pump bottom) as 3 to 6 inches $(0.076$ to $0.15 \mathrm{~m}$ ) above tank bottom. Thus, we used rotating mixer pump models to further evaluate the alternative pump's potential mixing performance at these heights as well as reference Case 3 at 16.9 inches $(0.43 \mathrm{~m})$ elevation. We assumed that the sludge thickness was 125 inches $(3.17 \mathrm{~m})$ instead of 22 inches $(0.56 \mathrm{~m})$ because the former thickness would be more indicative of the mixer pumps' sludge mobilization ability. Thus, we evaluated Cases 3, 7, 8, and 9 (see Table 3.1) with rotating mixer pump models.

The 75-ft- (23-m-) diameter rotating mixer pump models contain twenty 30-inch- (76-cm-) diameter airlift circulators and a 33-inch- (84-cm-) diameter steam heating coil. These airlift circulators and heating coil are suspended approximately 30 inches $(0.76 \mathrm{~m})$ above the tank bottom as in some Hanford DSTs (e.g., AZ-102). Because they potentially act as obstacles for the jets to mix the waste, we included the airlift circulators and heating coils in the rotating mixer pump models with two rotating pumps. The two 300-hp alternative pumps each have a 27 -inch(0.67-m-) diameter withdrawal inlet and two 6-inch- (0.15-m-) diameter nozzles that inject 60$\mathrm{ft} / \mathrm{sec}(18.3 \mathrm{~m} / \mathrm{s})$ jets (see Figure 2.3). Because these two pumps are $22 \mathrm{ft}(6.7 \mathrm{~m})$ away from the tank center on opposite sides of the tank and rotate at $0.2 \mathrm{rpm}$ in a synchronized mode, we simulated the right half of the tank based on symmetry. Thus, within the actual simulation domain, there is one rotating pump with two opposing jets.

Case 3 is the alternative pump reference case, which produces the same sludge erosion as the baseline pump (Case 1), as discussed in Section 3. As stated previously, the alternative pump has the injection nozzles at the bottom, while the baseline pump has them at the top.

Figure 4.1 presents vertical cutoffs showing the initial conditions of this rotating mixer pump model for Case 3 . The top plot is along the 3 o'clock vertical plane (vertical plane $\mathrm{I}=2$ ), showing the jet at first directed toward the 125-inch- (3.17-m-) thick sludge layer in this vertical plane. The supernatant liquid is 221 inches $(5.618 \mathrm{~m})$ deep, totaling 346 inches $(8.788 \mathrm{~m})$ of waste in the tank. We diluted the sludge just around the pump to start the simulation, as we did for the non-rotating mixer pump models, to ease pump startup. At this time, the jet velocity is listed as $10.74 \mathrm{~m} / \mathrm{s}$ (at the right bottom of this upper plot), ramping up to the assigned injection velocity within a few seconds. At this initial time, there is another jet (opposite the jet shown in the top plot) shooting along the 9 o'clock position. These two jets rotate at $0.2 \mathrm{rpm}$ throughout the simulation. The middle and bottom figures are in vertical planes 11 and 15 , which are oriented at $81^{\circ}$ and $117^{\circ}$, respectively, counterclockwise from vertical plane $\mathrm{I}=2$. Each vertical plane (I=2, 11, 15, or any other plane) has a different distance from the pump to the tank wall because the mixer pump is $22 \mathrm{ft}(6.7 \mathrm{~m})$ off tank center. Vertical planes 2 and 15 have the shortest $(15.5 \mathrm{ft}$ or $4.72 \mathrm{~m})$ and longest $(43.6 \mathrm{ft}$ or $13.3 \mathrm{~m})$ distances to the tank wall. All three plots also show three of the 20 airlift circulators. 



Figure 4.1. Case 3 (alternative pump reference case: pump $0.429 \mathrm{~m}$ above tank bottom, 3.17-m sludge): Initial Vertical Distributions of Initial Conditions of Velocity and Tank Waste 
The rotating mixer pump models took a much longer time (a little over one simulation hour) to reach the final sludge erosion condition than the non-rotating mixer pump models, which took less than 20 simulation minutes. The predicted vertical distributions of the velocity and solid volume fraction for Case 3 (alternative pump reference case) after reaching the steady erosion state (70 simulation minutes) are shown in Figure 4.2. Again the top, middle, and bottom plots are those in vertical planes $I=2,11$, and 15 . These plots show that the two rotating jets skimmed the sludge and did not remove the sludge up to the tank wall along vertical planes 11 and 15 . The middle plot indicates that the rotating jets eroded the sludge beyond an airlift circulator, but the bottom plot reveals another airlift circulator still buried in the sludge.

As the alternative pumps were lowered from the reference Case 3 level, the two rotating jets for all three cases eroded more sludge than those of the reference case. Predicted velocity and solid concentrations at 70 simulation minutes for Cases 7 through 9 are shown in Figures 4.3 through 4.5, respectively; the results of these four cases are summarized in Table 4.1 and Figures 4.6 and 4.7.

These simulation results indicate that Cases 7 through 9 [2.9 inches $(0.074 \mathrm{~m}), 4.6$ inches $(0.116 \mathrm{~m})$, and 6.2 inches $(0.159 \mathrm{~m})$ ] mobilized almost the same amount of solids $(48 \sim 51 \mathrm{vol} \%$ of the total tank solids). While reference Case 3 [16.9-inch $(0.429-\mathrm{m})$ case] mobilized 38.6 vol\% of the total solids. This trend is basically the same as those observed with non-rotating mixer pump models with both 125-inch (3.17-m) and 22-inch (0.56-m) thick sludge, except that Case 7 (pump 2.9 inches above tank bottom) eroded slightly less (2.9 and 2.3\% less, respectively) sludge than Cases 8 and 9 (pumps 4.6 and 6.2 inches above tank bottom). This is probably due to slight differences in the two opposing tank wall effects (restricting vertical mixing and exerting bottom friction) on the jet spread in these three cases, as was discussed in Section 3.2. The modeling shows that with the pump injection level (pump bottom level) lowered to six inches above tank bottom, the pumps would erode approximately 12 vol\% more of the total tank solids than the reference case. Relatively speaking, these lower three cases would erode 25 $33 \%$ more solids than the reference case, as indicated in Table 4.1.

Table 4.1. Summary of Alternative Pump Reference Case (Case 3) and Cases 7 through 9

\begin{tabular}{|c|c|c|c|c|c|}
\hline $\begin{array}{c}\text { Case } \\
\text { Number }\end{array}$ & $\begin{array}{c}\text { Injection } \\
\text { above Tank } \\
\text { Bottom } \\
\text { (in.) }\end{array}$ & $\begin{array}{c}\text { Inlet } \\
\text { above Tank } \\
\text { Bottom } \\
\text { (in.) }\end{array}$ & $\begin{array}{c}\text { Erosion } \\
\text { of Total } \\
\text { Tank Solids } \\
(\boldsymbol{\%})\end{array}$ & $\begin{array}{c}\text { Normalized } \\
\text { Relative } \\
\text { Erosion } \\
(\boldsymbol{\%})\end{array}$ & $\begin{array}{c}\text { Effective } \\
\text { Clearing } \\
\text { Radius } \\
\text { (ft) }\end{array}$ \\
\hline Case 7 & 2.9 & 26.0 & 48.2 & 125 & 26.0 \\
\hline Case 8 & 4.6 & 27.7 & 51.1 & 133 & 26.8 \\
\hline Case 9 & 6.2 & 29.4 & 50.5 & 131 & 26.6 \\
\hline Case 3 & 16.9 & 40.1 & 38.6 & 100 & 23.3 \\
\hline
\end{tabular}





Figure 4.2. Case 3 (alternative pump reference case: pump $0.429 \mathrm{~m}$ above tank bottom, 3.17-m sludge): Predicted Vertical Distributions of Velocity and Solid Volume Fraction at 70 Simulation Minutes 

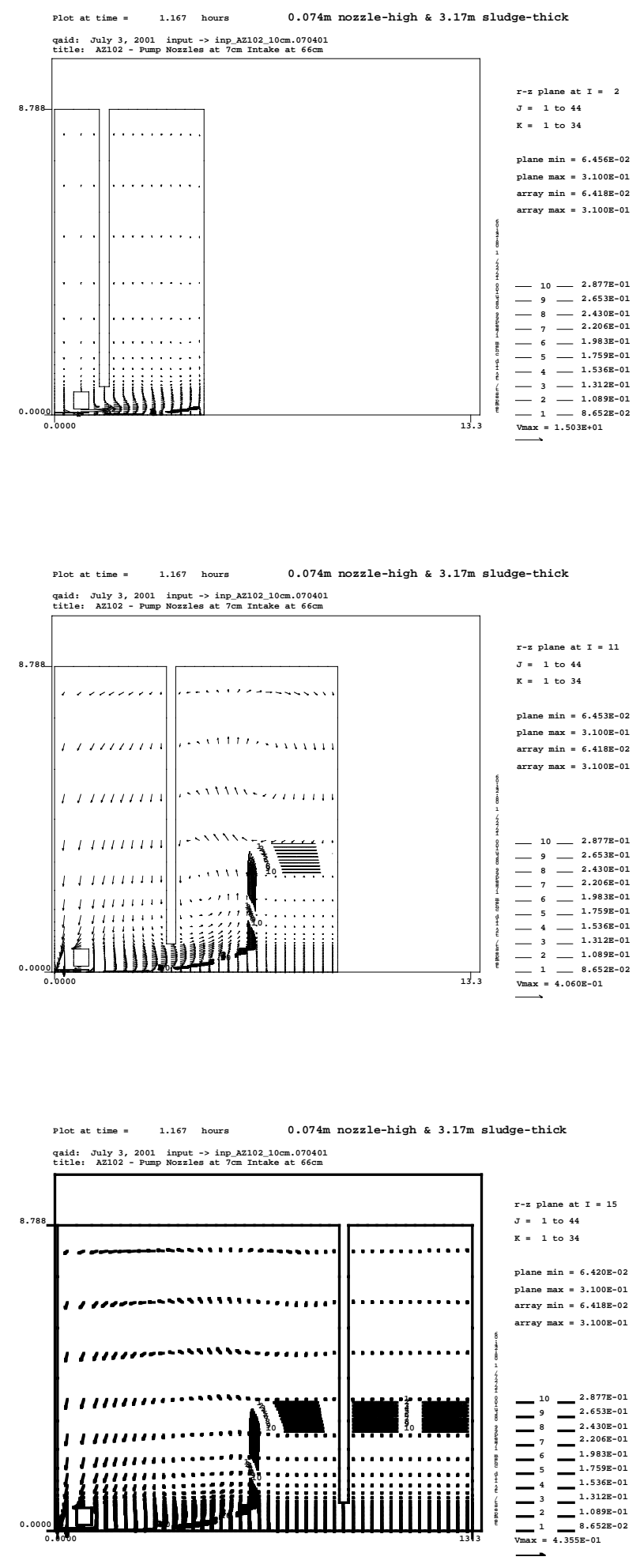

Figure 4.3. Case 7 (alternative pump $0.074 \mathrm{~m}$ above tank bottom, 3.17-m sludge): Predicted Vertical Distributions of Velocity and Solid Volume Fraction at 70 Simulation Minutes 

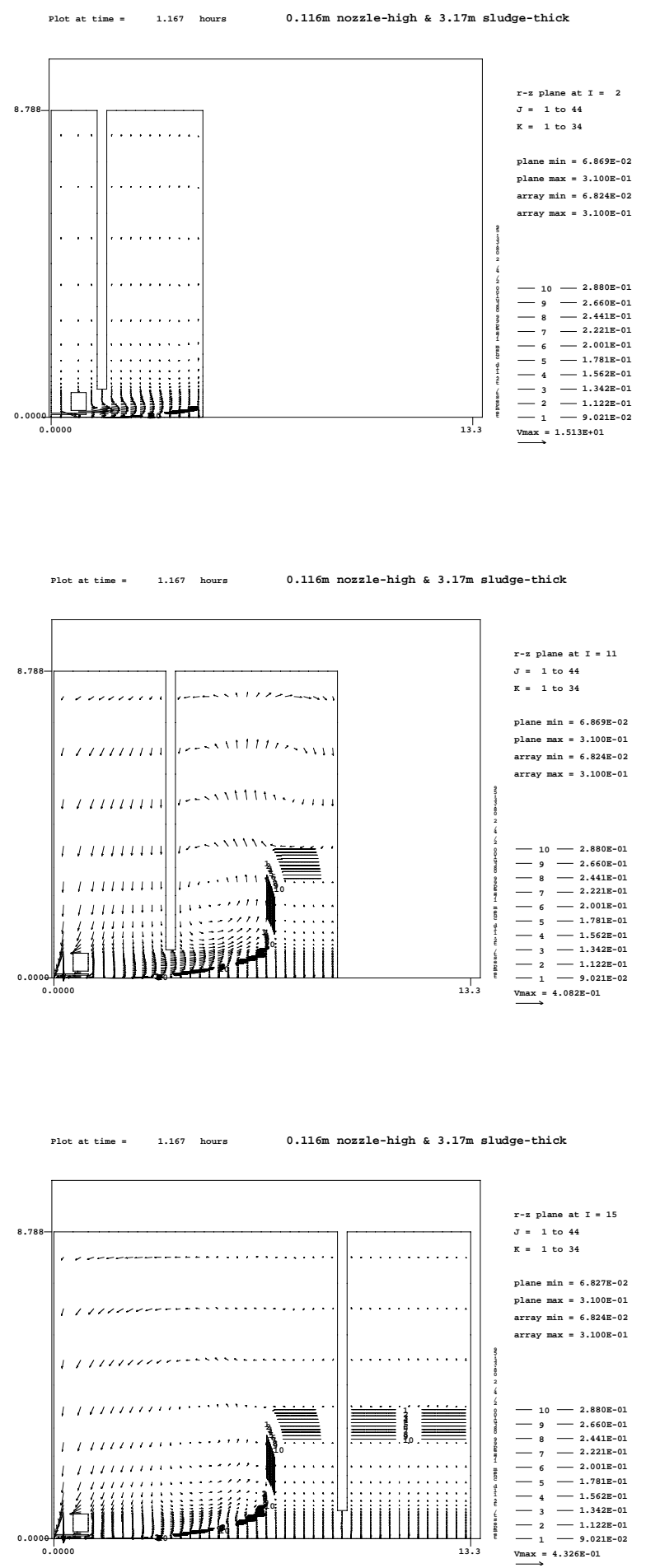

Figure 4.4. Case 8 (alternative pump $0.116 \mathrm{~m}$ above tank bottom, 3.17-m sludge): Predicted Vertical Distributions of Velocity and Solid Volume Fraction at 70 Simulation Minutes 

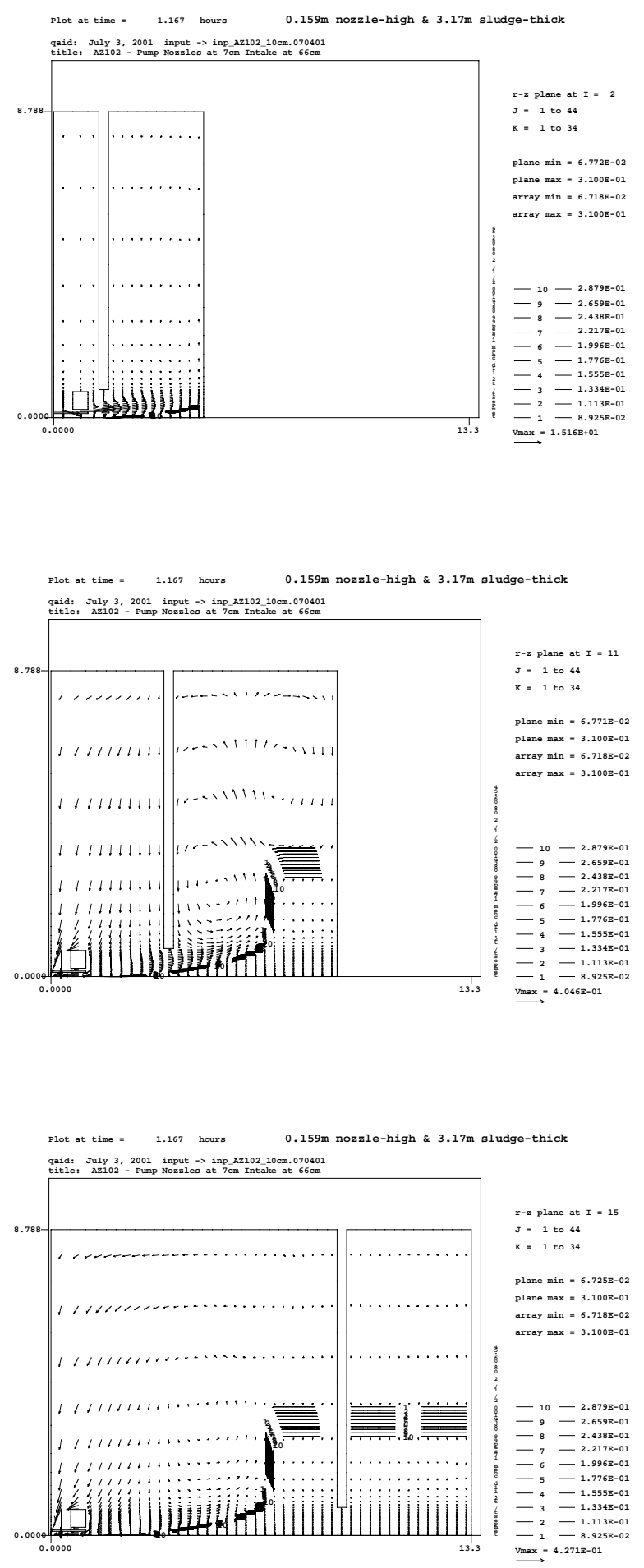

Figure 4.5. Case 9 (alternative pump $0.159 \mathrm{~m}$ above tank bottom, 3.17-m sludge): Predicted Vertical Distributions of Velocity and Solid Volume Fraction at 70 Simulation Minutes 


\section{Erosion Volume Percent: 125-inch Sludge}

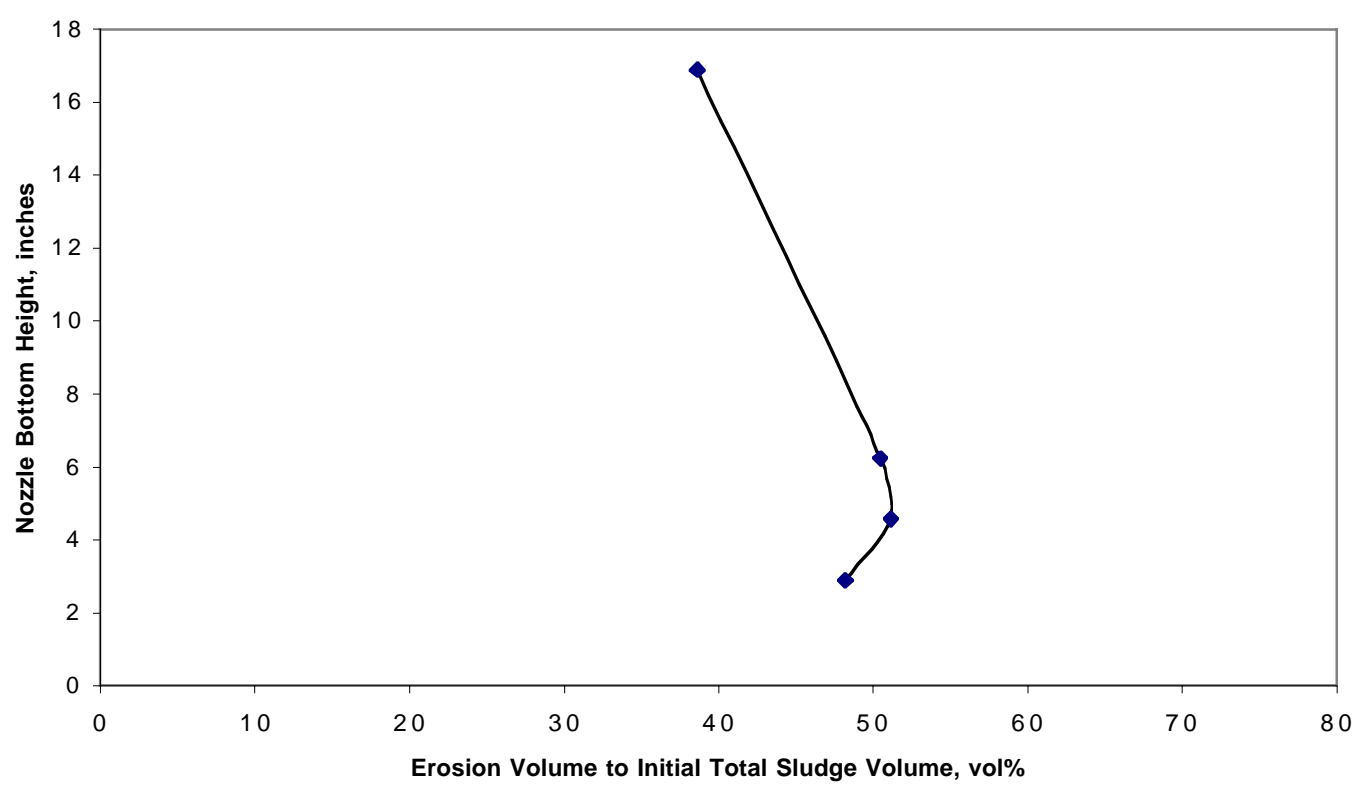

Figure 4.6. Predicted Mobilized Sludge Volume Percent Compared with Initial Total Sludge Volume for Sludge Thickness of 125 inches $(3.17 \mathrm{~m})$

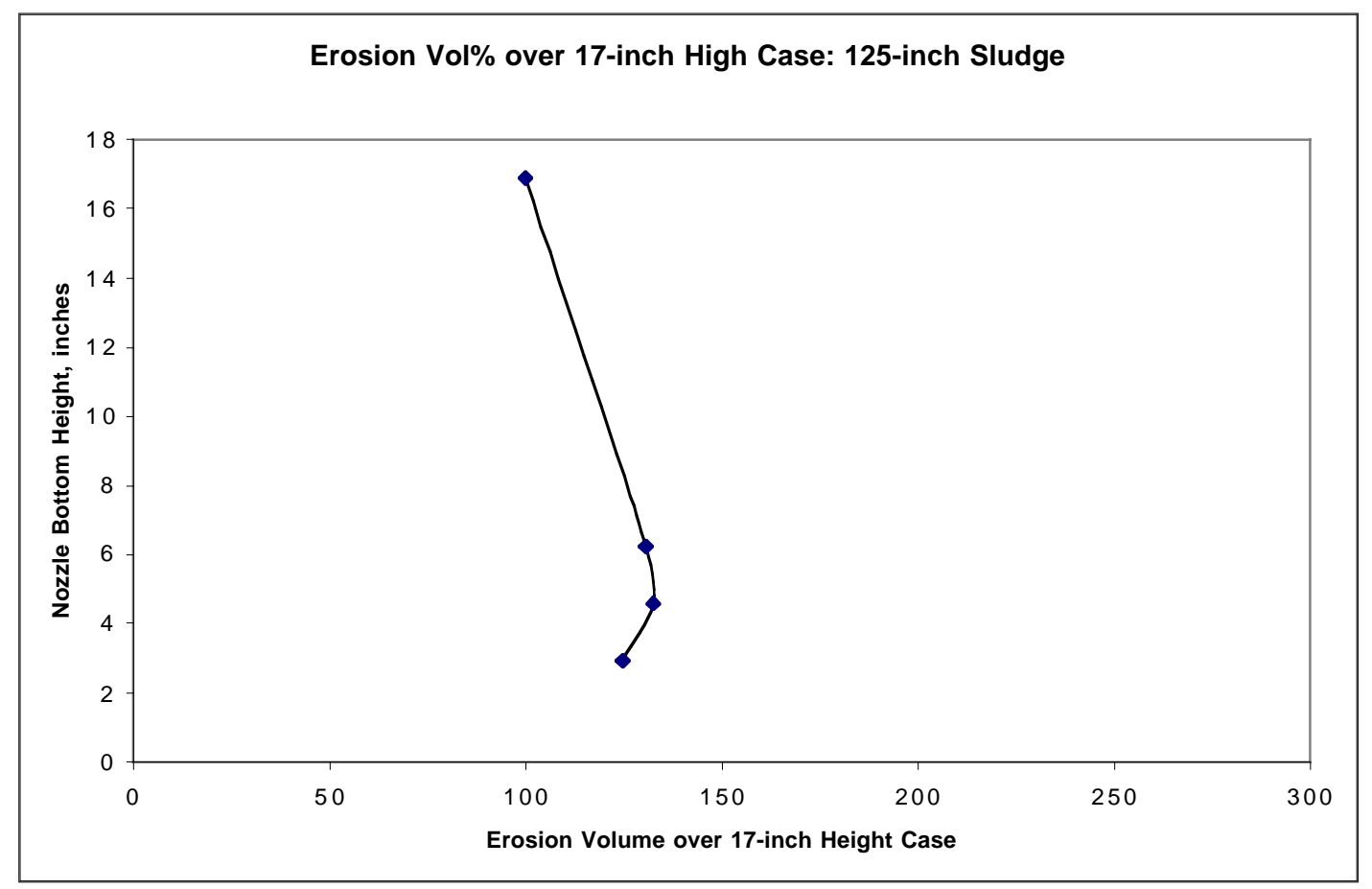

Figure 4.7. Predicted Vol\% of Eroded Sludge Normalized by Case 3 (reference alternative pump case) for Sludge Thickness of 125 inches (3.17 m) 


\subsection{Summary and Conclusions}

A horizontal jet injected from near the tank bottom may potentially erode more sludge and saltcake than a jet placed away from the bottom, as some experiments of air-to-air and water-towater jets imply (Rajaratnam and Subramanya 1968, Pani and Dash 1983). Placing the intake at the top of the pump enables the injection nozzles to be placed at the pump bottom; thus the injection nozzles can be placed closer to the tank bottom than the baseline pump with the injection nozzle at the top. Placing the inlet at the top of a centrifugal pump also potentially make it easier to start up mixer pumps, if a vertical distribution of the solid concentrations is non-uniform, such as at those times during and shortly after water lancing prior to the mixer pump operation. However, a higher pump inlet can limit the operable range of the waste thickness and potentially reduce solid erosion by withdrawing lighter fluids (a liquid waste or a slurry with less solids concentration) and thus by making the mixer pump jet more buoyant.

The objective of the study was to evaluate the mixing-performance of the pumps for the W-211 Project, "Initial Tank Retrieval System," so they can determine whether their DST waste retrieval operation should use the baseline pump with top injection nozzles or alternative pumps with bottom injection nozzles. To achieve this objective, we conducted three-dimensional TEMPEST computer simulations to answer the following questions:

- How much more solids, if any, can be mobilized by the alternative pump with injection nozzles at the bottom?

- What is the optimal elevation for the alternative pump installment in DST if the alternative pump is more effective than the baseline pump at mobilizing the solids?

We selected eight pump elevation configurations ranging from the pump sitting on the tank bottom to $1.46,2.91,4.58,6.25$, and 32.7 inches $(0.037,0.074,0.12,0.16,0.43$, and $0.83 \mathrm{~m}$ ) above the tank bottom. The sludge thickness was designated as either 22 inches $(0.56 \mathrm{~m})$ or 125 inches $(3.17 \mathrm{~m})$. Thus a total of 16 baseline and alternative pump cases were evaluated. We assigned waste properties (e.g., density and rheology) to be the same as those of AZ-102 waste, because it is more difficult to mobilize the sludge (e.g., those in AZ-101 and AZ-102) than saltcakes (e.g., those in AN-104 and AN-105), and AZ-102 sludge has detailed rheology data and is representative of DST sludge.

This study adapted the following two-step evaluation approach to obtain mixing performance evaluation in a timely manner:

Step 1: evaluate all 16 baseline and alternative pump cases with the use of the single nonrotating mixer pump model to select four cases for further detained evaluation

Step 2: evaluate four selected cases with the rotating mixer pump models to conduct more realistic mixing performance evaluation.

According to the non-rotating mixer pump model simulation results, the elevation of the intake by itself [whether it is placed at the bottom of the pump (like the baseline pump) or the top 
of the pump (like the alternative pump)] does not affect the pump's ability to erode the waste when the injection nozzle levels of both pumps are placed at the baseline nozzle injection level.

These non-rotating mixer pump model results also indicate that the closer the pump injection elevation is to the tank bottom, the greater the sludge erosion. Thus, all alternative pump cases with lower injection levels than the baseline pump would erode more sludge than the baseline case. When the pump injection nozzle is placed on the bottom of the tank, it would mobilize 200 $\sim 900 \%$ more sludge than a pump located 17 inches above the tank bottom. When the pump injection is 1.5 inches $(0.038 \mathrm{~m})$ above the tank bottom, it erodes $140 \sim 450 \%$ more sludge than the baseline pump does at 17 inches. When the injection level is 3 to 6 inches (0.076 to $0.15 \mathrm{~m})$ above the tank bottom, the amounts of eroded sludge are basically the same at all these elevations; the pump erodes $10 \sim 20 \%$ more sludge than the baseline pump at the 17-inch injection level.

There may be some engineering difficulties (e.g., potentially encountering the non-flat tank bottom, or pumps accidentally hitting the tank bottom during the installation) in placing large 300-hp mixer pumps within approximately 6 inches $(0.15 \mathrm{~m})$ of the tank bottom. Thus, the elevations of the bottom of the mixer pumps (the bottom of the injection nozzles) between 3 and 6 inches $(0.076$ and $0.15 \mathrm{~m})$, as well as the alternative pump's reference [pump bottom 16.9 inches $(0.43 \mathrm{~m})$ above tank bottom] were selected for further evaluation with the more realistic rotating mixer pump models with 125 -inch $(3.17-\mathrm{m})$ sludge.

These more realistic simulation results shown in Table 5.1 indicate that the alternative pump installed 2.9 inches $(0.074 \mathrm{~m}), 4.6$ inches $(0.116 \mathrm{~m})$, and 6.2 inches $(0.159 \mathrm{~m})$ above the tank bottom mobilized almost the same amount of solids (48 51 vol\% of the total tank solids). While the reference case [alternative pump with injection nozzles at 16.9 inch $(0.429 \mathrm{~m})$ ] mobilized $39 \mathrm{vol} \%$ of the total solids. This trend is basically the same as those observed with non-rotating mixer pump models with both 125 -inch- $(3.17-\mathrm{m})$ and 22 -inch- $(0.56-\mathrm{m})$ thick sludge. Thus, if the pump's injection level (pump bottom level) were lowered to 6 inches $(0.15$ m) above the tank bottom, the pumps would erode approximately $10 \sim 12$ vol\% more of the total tank solids than the reference case would. Relatively speaking, these three lower elevation cases would erode $25 \sim 33 \%$ more solids than the reference case. These results provide a mixing performance technical basis for the W-211 Project, "Initial Tank Retrieval Systems," to determine which pump configuration should be used for their DST waste retrieval activity.

Table 5.1. Summary of Alternative Pump Cases

\begin{tabular}{||c|c|c|c|c||}
\hline $\begin{array}{c}\text { Pump Bottom } \\
\text { Height above } \\
\text { Tank Bottom } \\
\text { (in.) }\end{array}$ & $\begin{array}{c}\text { Intake Height } \\
\text { above Tank } \\
\text { Bottom } \\
\text { (in.) }\end{array}$ & $\begin{array}{c}\text { Erosion of the } \\
\text { Total Tank Solids } \\
(\text { vol\%) }\end{array}$ & $\begin{array}{c}\text { Normalized } \\
\text { Relative } \\
\text { Erosion } \\
(\boldsymbol{\%})\end{array}$ & $\begin{array}{c}\text { Effective } \\
\text { Cleaning } \\
\text { Radius } \\
\text { (ft) }\end{array}$ \\
\hline 2.9 & 26.0 & 48.2 & 125 & 26.0 \\
\hline 4.6 & 27.7 & 51.1 & 133 & 26.8 \\
\hline 6.2 & 29.4 & 50.5 & 131 & 26.6 \\
\hline 16.9 & 40.1 & 38.6 & 100 & 23.3 \\
\hline
\end{tabular}




\subsection{References}

Carlson AB, PJ Certa, TM Hohl, HS Fisher, SJ Geelgood, JR Bellomy, TW Crawford, DC Hedengren, AM Templeton, DG Douglas, and WJ Ulbricht Jr. 2001. Test Report, 241-AZ101 Mixer Pump Test. RPP-6548 Rev. 1, CH2M HILL Hanford Group, Inc., Richland, WA.

Gephart RE and RE Lundgren. 1997. Hanford Tank Cleanup: A Guide to Understanding the Technical Issues. PNNL-10773, Pacific Northwest National Laboratory, Richland, WA.

Herting DL. 1997. Results of Dilution Studies with Waste from Tank 241-AN-105. HNF-SDWM-DTR-046 Rev. 0, Numatec Hanford Corporation, Richland, WA.

Jewett JR, SD Estey, L Jensen, NW Kirch, DA Reynolds, and Y Onishi. 2002. Values of Particle Size, Particle Density, and Slurry Viscosity to Use in Waste Feed Delivery Transfer System Analysis. RPP-9805 Rev. 1, Numatec Hanford Company, Richland, WA.

Onishi Y, R Shekarriz, KP Recknagle, PA Smith, J Liu, YL Chen, DR Rector, and JD Hudson. 1996. Tank SY-102 Waste Retrieval Assessment: Rheological Measurements and Pump Jet Mixing Simulation. PNNL-11352, Pacific Northwest National Laboratory, Richland, WA.

Onishi Y and DS Trent. March 1999. "Mobilization Modeling of Erosion-Resisting Radioactive Tank Waste." Proceedings of Rheology in the Mineral Industry II, Kahuku, Oahu, Hawaii. United Engineering Foundation, New York, pp. 45-56.

Onishi Y, KP Recknagle, and BE Wells. 2000. Pump Jet Mixing and Pipeline Transfer Assessment for High-Activity Radioactive Wastes in Hanford Tank 241-AZ-102. PNNL-13275, Pacific Northwest National Laboratory, Richland, WA.

Pani BS and RN Dash. 1983. “Three-Dimensional Reattached Wall Jet.” La Houille Blanche/N 38(1)27-113.

Powell MR, GR Golcar, CR Hymas, and RL McKay. 1995a. Fiscal Year 1993 1/25-Scale Sludge Mobilization Testing. PNL-10464, Pacific Northwest National Laboratory, Richland, WA.

Powell MR, CM Gates, CR Hymas, MA Sprecher, and NJ Morter. 1995b. Fiscal Year 1994 1/25-Scale Sludge Mobilization Testing. PNL-10582, Pacific Northwest National Laboratory, Richland, WA.

Rajaratnam N and K Subramanya. 1968. "Plane Turbulence Reattached Wall Jet." Journal of the Hydraulic Division, ASCE 94(HY1):95.

Ryan GW. 1995. Tank Characterization Report for Double Shell Tank 241-AZ-102. WHC-SDWM-ER-411 Rev. 0, Westinghouse Hanford Company, Richland, WA. 
Stewart CW, JM Alzheimer, ME Brewster, G Chen, RE Mendoza, HC Reid, CL Shepard, and G Terrones. 1996. In Situ Rheology and Gas Volume in Hanford Double-Shell Waste Tanks. PNNL-11296, Pacific Northwest National laboratory, Richland, WA.

Trent DS and LL Eyler. 1993. TEMPEST: A Computer Program for Three-Dimensional, TimeDependent Computational Fluid Dynamics. PNL-8857 Vol. 1, Version T, Mod 2, Pacific Northwest National Laboratory, Richland, WA. 


\section{Distribution}

No. of

Copies

Offsite

M. Katona

Department of Civil and Environmental Engineering

Washington State University

Pullman, WA 99164

5 CA Majumder

University of Minnesota

Supercomputer Institute

1200 Washington Ave. So.

Minneapolis, MN 55415-1227

2 Oak Ridge National Laboratory

PO. Box 2008

Oak Ridge, TN 37831

Attn: CP McGinnis

TD Welch

DA Yuen

University of Minnesota

Supercomputer Institute

1200 Washington Ave. So.

Minneapolis, MN 55415-1227

\section{Onsite}

6 DOE Richland Operations Office

J Cruz

H6-60

JJ Davis (5)

H6-60

29 Hanford Contractors

RE Bauer

SR Briggs

S7-73

JW Cammann
No. of

Copies

PJ Certa

R3-73

A-MF Choho

R3-73

TJ Conrads

R3-83

DW Crass

S7-90

JD Galbraith

R3-73

PW Gibbons

K9-91

CE Grenard

R3-73

DL Herting

T6-07

JL Jewett

G3-43

NW Kirch

R2-11

JG Kristofzski

R2-39

EW Martinen (5)

R3-47

RE Raymond

R2-50

DA Reynolds

R2-11

CA Rieck (5)

R3-47

RW Root

R2-50

WT Thompson

S7-90

JE Van Beek

50 Pacific Northwest National Laboratory

GH Beeman

SQ Bennett

JR Bontha

JW Brothers

JL Buelt

PA Gauglitz

WL Kuhn

DE Kurath

PA Meyer

TE Michener

Y Onishi (30)

KP Recknagle

CW Stewart

WC Weimer

ST Yokuda (5)

Information Release (2)
K9-18

K7-90

K6-24

K9-20

K9-09

K6-28

K7-15

P7-28

K7-15

K7-15

K7-15

K7-15

K7-15

K9-09

K7-15

K1-06 